\title{
16 Parhyale hawaiensis, Crustacea
}

\author{
John Rallis, Gentian Kapai and Anastasios Pavlopoulos
}

\section{CONTENTS}

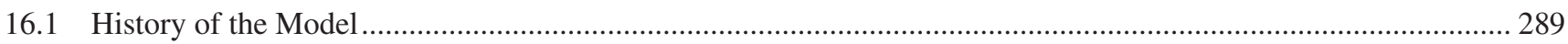

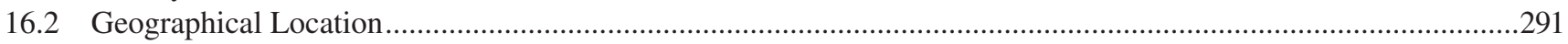

16.3 Life Cycle

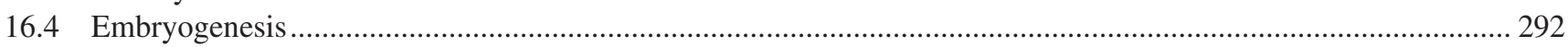

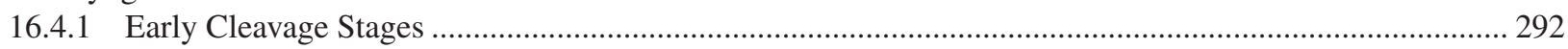

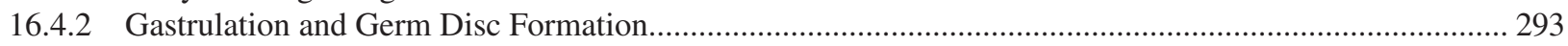

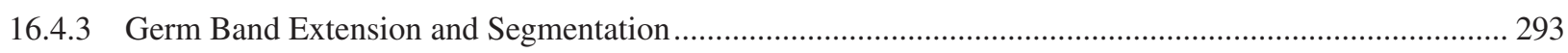

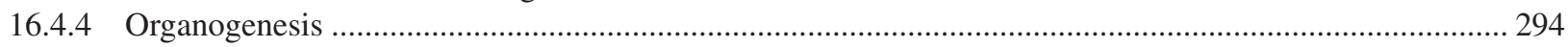

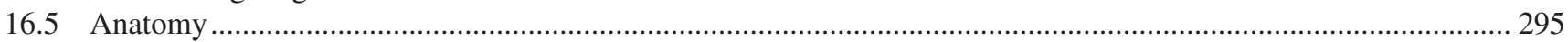

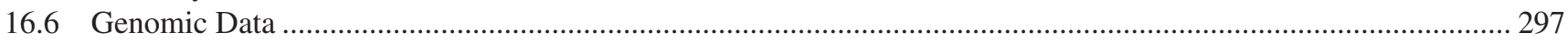

16.7 Functional Approaches: Tools for Molecular and Cellular Analyses................................................................... 299

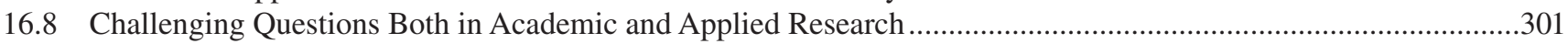

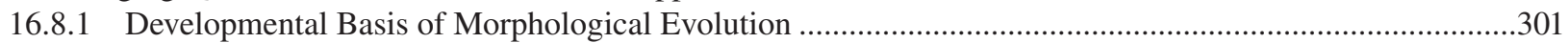

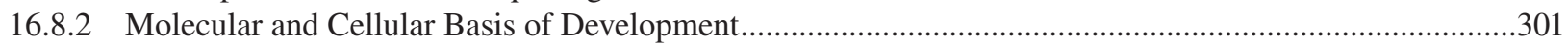

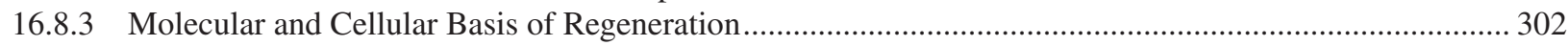

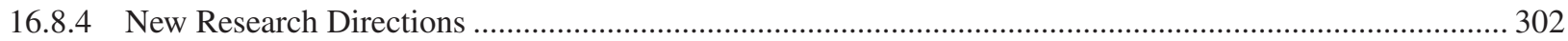

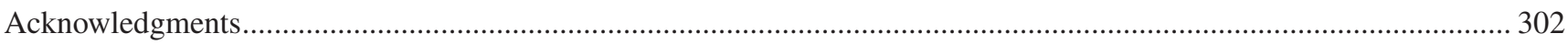

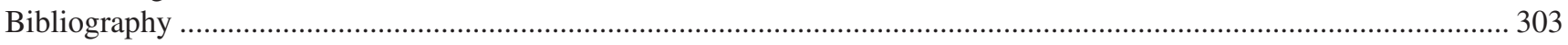

\subsection{HISTORY OF THE MODEL}

The marine crustacean species Parhyale hawaiensis (hereafter referred to as Parhyale) was first described by James D. Dana in 1853 from the Hawaiian island of Maui (Dana 1853; Shoemaker 1956; Myers 1985). It was first introduced in the laboratory of Prof. Nipam Patel in 1997 from a population that was collected from the filtration system of the Shedd Aquarium in Chicago (Rehm et al. 2009e). Since the early 2000 s, it has emerged as an attractive experimental organism for modern biological and biomedical research. An increasing number of laboratories in America and Europe have embraced this model system for molecular, cellular, ecological, evolutionary, developmental genetic and functional genomic studies (Stamataki and Pavlopoulos 2016).

Parhyale is a member of the order Amphipoda, a diverse group of crustaceans with more than 10,000 identified species (Figure 16.1a) (Horton et al. 2020). Besides its biological and technical qualities described in the following sections, Parhyale was selected for its position in the arthropod phylogenetic tree. Amphipoda belong to the class Malacostraca that comprises well-known and nutritionally important crustaceans from the order Decapoda such as crabs, lobsters, shrimps and crayfish, as well as other familiar crustaceans such as mantis shrimps (Stomatopoda), woodlice (Isopoda), krill (Euphausiacea) and others (Figure 16.1b).
Although many high-level and low-level phylogenetic relationships still remain unresolved, several molecular phylogenetic and phylogenomic analyses have improved our knowledge on the relationships between malacostracans and the other crustacean and arthropod groups (Giribet and Edgecombe 2019). It is now almost universally accepted that insects (Hexapoda) represent a terrestrial lineage of crustaceans that together with the crustaceans constitute the monophyletic taxon Pancrustacea (Figure 16.1c). Within Pancrustacea, Remipedia are increasingly supported as the sister group to Hexapoda that together with Branchiopoda and Cephalocarida form a group called Allotriocarida (von Reumont et al. 2012; Schwentner et al. 2017). Malacostraca are more closely related to Copepoda and Thecostraca (with their exact relationships still unresolved) and form the sister group to Allotriocarida called Multicrustacea (Regier et al. 2010; Lozano-Fernandez et al. 2019). Finally, Oligostraca constitute the third major pancrustacean clade containing the Ostracoda, Mystacocarida, Branchiura and Pentastomida (Regier et al. 2010; Oakley et al. 2013). High-level arthropod relationships have been also adequately resolved, ending centuries of debates (Giribet and Edgecombe 2019). Myriapoda (centipedes, millipeds and allies) have been placed as the sister group to Pancrustacea, in a clade known as Mandibulata (jawed arthropods), and together with the Chelicerata (sea spiders, horseshoe crabs and arachnids) 
they form the three main branches of extant Arthropoda (Figure 16.1c).

This improved phylogeny seeded the development of suitable crustacean species as experimental models for comparative studies to understand the conservation and divergence of developmental patterning mechanisms during pancrustacean and arthropod evolution. The insect Drosophila melanogaster, which is one of the premier animal models for developmental genetic and genomic research, has attracted disproportionately more attention compared to other emerging insect, crustacean, myriapod and chelicerate models. Acknowledging all the major contributions that Drosophila research has made in revealing many of the basic principles of animal development, its lineage represents only a tiny fraction of the morphological diversity and developmental strategies employed by arthropods alone. Over the last two decades, the availability of broadly applicable experimental approaches has bridged the technological gap between (a)

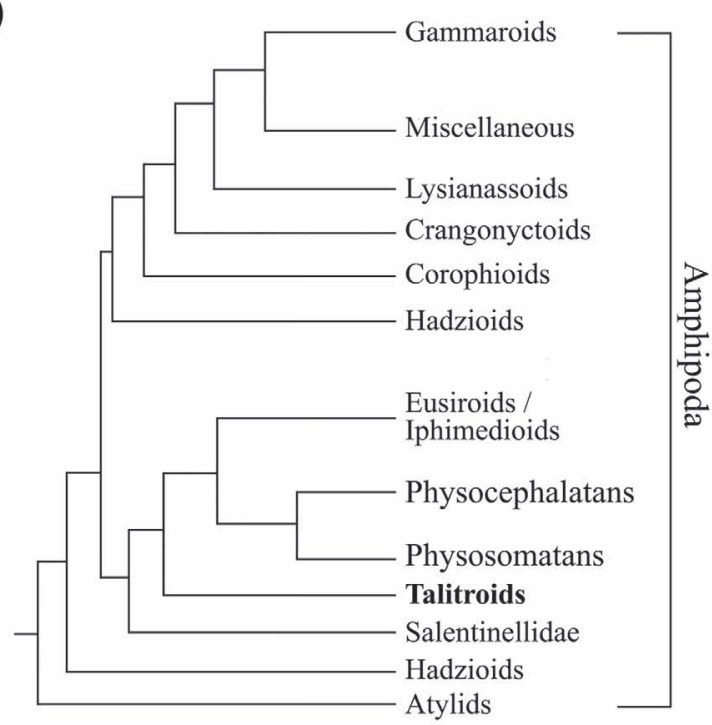

(c)

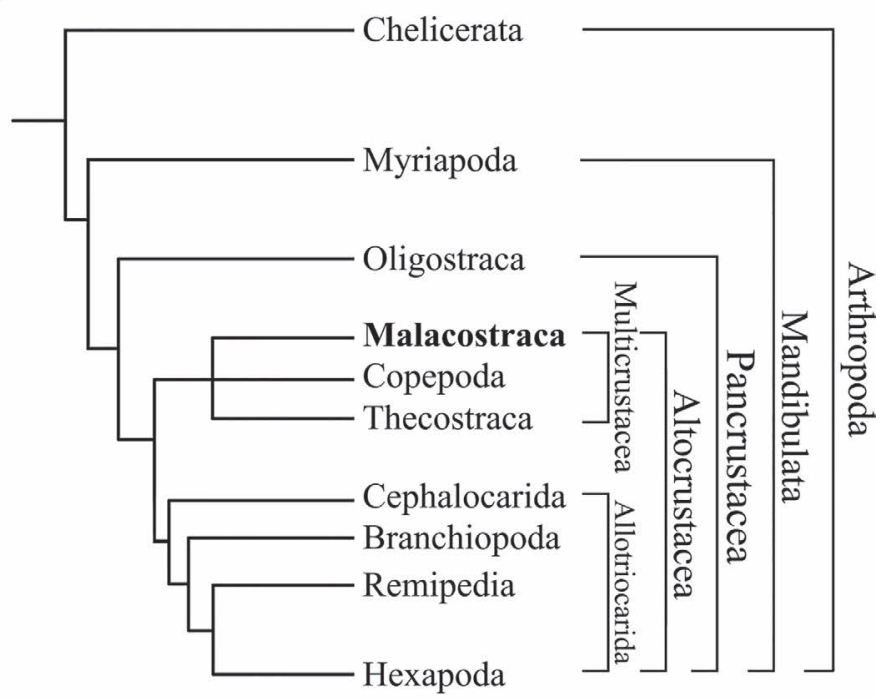

(b)

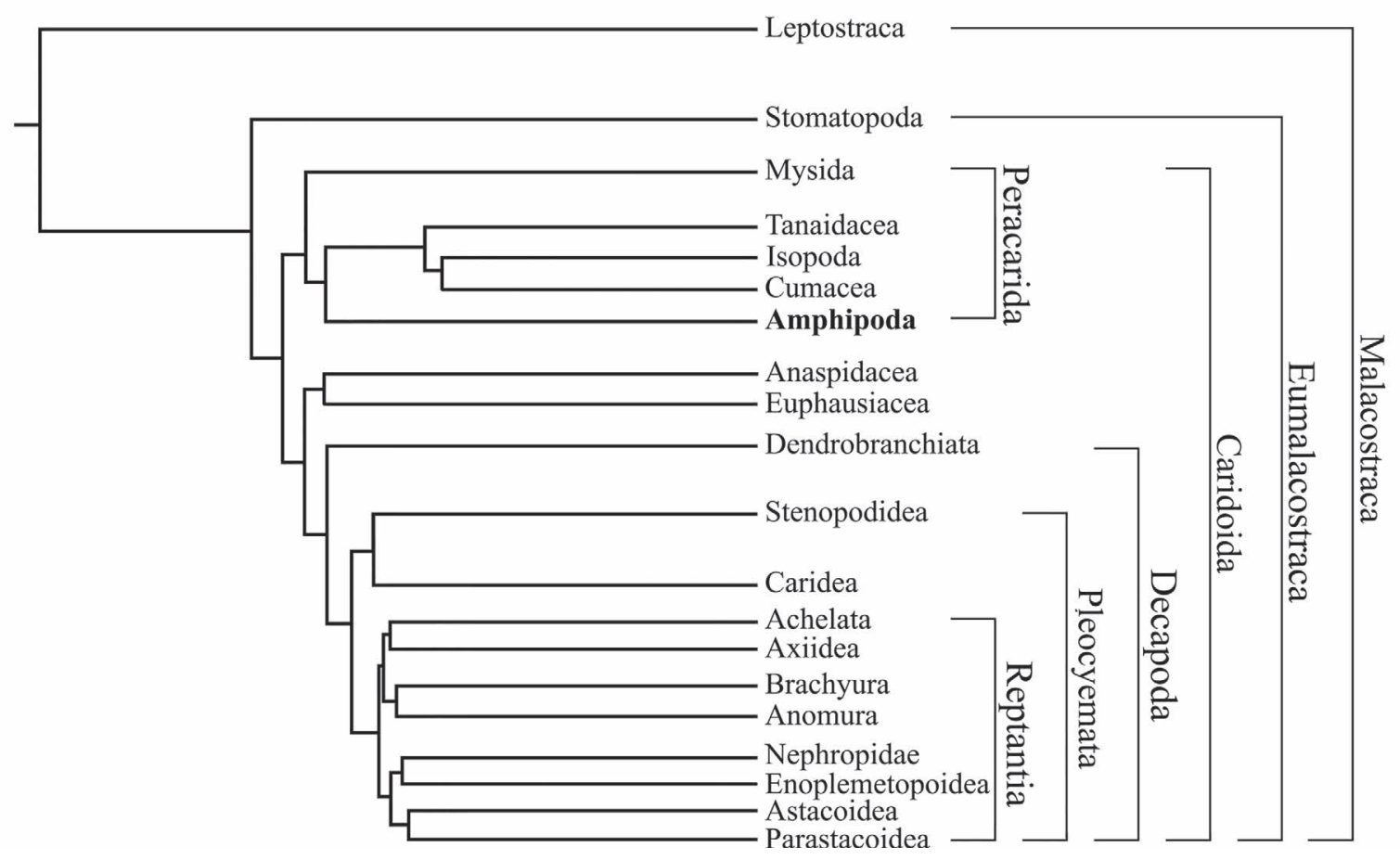

FIGURE 16.1 Phylogenetic affiliation of Parhyale hawaiensis. (a) One of the few available molecular phylogenies depicting the relationships between amphipod lineages, according to Copilaş-Ciocianu et al. 2020. Parhyale is a marine talitrid amphipod that belongs to the family Hyalidae. (b) Phylogenetic relationships within Malacostraca, according to (Schwentner et al. 2018). Note that many topologies are poorly supported and remain essentially unresolved. Parhyale is a peracarid amphipod. (c) Molecular tree of the arthropods, as reviewed by Giribet and Edgecombe 2019. Parhyale is a Malacostracan crustacean. 
Drosophila and emergent arthropod models enabling both mechanistic insights into biological diversity, as well the study of unique traits and biological processes that are not accessible in standard model systems.

Parhyale is currently one of the very few available models representative of malacostracans, crustaceans and marine animals in general that is experimentally tractable and supported by a continuously expanding toolkit of techniques and resources (Kao et al. 2016). As a result, studies in Parhyale are increasing in scope and depth beyond the descriptive level, hypotheses can be tested functionally at a higher level of sophistication and novel discoveries are making research headlines (BBSRC Business Magazine 2017).

\subsection{GEOGRAPHICAL LOCATION}

Amphipods have inhabited almost all aquatic (marine, brackish and freshwater) environments, as well as moist terrestrial habitats, and play essential roles as detritovores or scavengers in nutrient recycling in these ecosystems (Copilaş-Ciocianu et al. 2020). Parhyale is an epibenthic detritovorous species with a worldwide, circumtropical distribution (Shoemaker 1956; Myers 1985). It lives in intertidal and shallow marine habitats, including bays, estuaries and mangrove litter; therefore, it can tolerate large changes in salinity, temperature and nutrient availability (Tararam et al. 1978; Poovachiranon et al. 1986).

Based on measurements of the population structure and dynamics in communities of intertidal shores, the Parhyale lifestyle is consistent with the opportunistic strategies adopted by epifaunal species inhabiting unpredictable

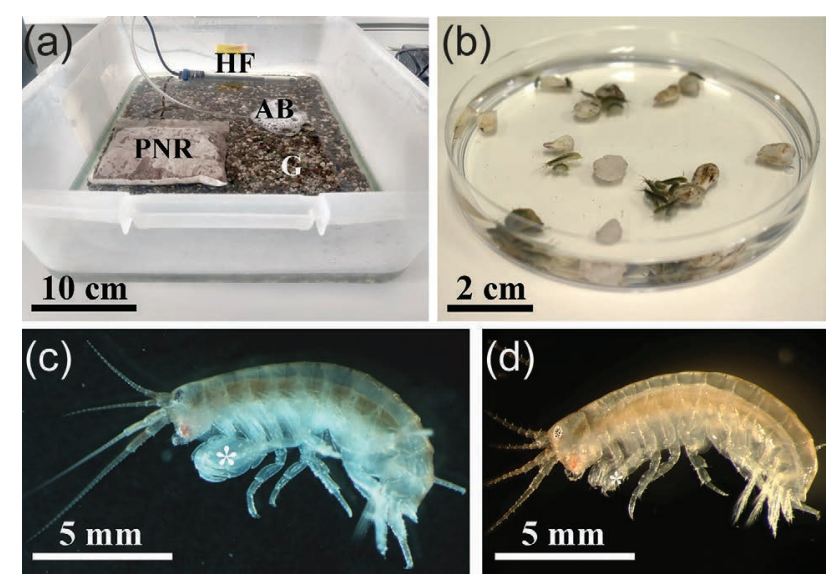

FIGURE 16.2 Parhyale hawaiensis as a laboratory experimental model. (a) Typical laboratory Parhyale culture in a plastic Tupperware (lid removed for the photo) containing artificial sea water, a layer of gravel $(\mathrm{G})$, an air bubbler $(\mathrm{AB})$ for aeration, a heating filament (HF) for a constant temperature at $26^{\circ} \mathrm{C}$ and a phosphate/nitrate remover (PNR) to keep the culture free of organic waste. (b) Petri dish with Parhyale mating pairs in precopulatory amplexus. (c) Adult male and (d) female Parhyale. Lateral views with anterior to the left and ventral to the bottom. The sexually dimorphic gnathopods are indicated with asterisks. environments (Alegretti et al. 2016). Population size varies during the year and grows rapidly during favorable environmental conditions. The rapid growth of Parhyale populations is attributed to their continuous reproductive capacity, a sex ratio biased toward females and multivoltinism (having several broods per season). The relatively low number of eggs per female (ranging between 5 and 30 per brood depending on the age and size of the female) is compensated for by the precocious sexual maturation of adults, as well as the low mortality of embryos and hatched juveniles that are kept by females in a ventral brood pouch. The average generation time of Parhyale in intertidal natural populations has been estimated at 3.5 months (Alegretti et al. 2016), but this is decreased to about 2 months in the laboratory. More broadly, this lifestyle enables Parhyale to thrive under controlled laboratory conditions, where the only major consideration is the continuous aeration of the cultures with air or water pumps due to their generally low tolerance to hypoxic conditions.

\subsection{LIFE CYCLE}

In the laboratory, Parhyale is cultured in large plastic containers on a bed of crushed coral gravel and covered in artificial sea water under continuous aeration (Figure 16.2a). Although they can tolerate a wide range of temperatures from at least $18^{\circ} \mathrm{C}$ to $30^{\circ} \mathrm{C}$, they are routinely kept at $26^{\circ} \mathrm{C}$ to standardize developmental timing. Parhyale are omnivorous; therefore, different labs have adopted different diets ranging from plain carrots to rich mixes of larval shrimp and fish flakes supplemented with fatty acids and vitamins. Under these conditions and with frequent feeding and water change regimes, Parhyale has in the laboratory a life cycle of about two months. This relatively short generation time and the ease and cost effectiveness to grow this marine crustacean in dense cultures, as well as the daily availability of hundreds of individuals at any desired developmental stage throughout the year, make Parhyale a convenient model system for research purposes.

Parhyale is a sexually dimorphic species (Figure 16.2bd). Adult males can be easily distinguished from females based on a pair of enlarged grasping appendages (the second pair of gnathopods) in their anterior thorax (Figure 16.2c, d). A sexually mature male uses the other first pair of unenlarged gnathopods to grasp and carry a female, guarding her against other males before copulation (Conlan 1991). The duration of this precopulatory amplexus varies from several hours to days, during which time the couple is capable of walking and swimming (Figure 16.2b). Shortly before copulation, the female molts, producing a new brood chamber (marsupium) under her ventral surface from flexible flaps (oostegites) extending medially from her thoracic appendages. The male then deposits sperm into the new marsupium, and the female ovulates, depositing her oocytes into the marsupium while the new exoskeleton is still flexible to allow their passage through the oviducts (Hyne 2011). The 
poorly understood process of fertilization takes place externally in the marsupium while the male and female separate. As noted earlier, Parhyale females lay about 5 to 30 eggs during each molting cycle depending on their age and size and can produce successive broods every few weeks during their lifetime. Considering also that females do not store sperm, this reproductive behavior is convenient for genetic research as single backcrosses and intercrosses can be set routinely to generate Parhyale inbred lines.

After fertilization, the embryos of each brood develop fairly synchronously inside the marsupium. Embryos at any stage of their development can be easily dissected or flashed out from the marsupial pouch of anesthetized gravid females (without sacrificing them) and cultured in Petri dishes in artificial seawater. Similar to the rest of amphipods, Parhyale are direct developers and lack intermediate larval stages (Figure 16.3). After about ten days of embryogenesis at $26^{\circ} \mathrm{C}$, the juveniles that hatch and then are released from the marsupium resemble miniature versions of the adult form. Juveniles increase in size through successive molts and reach sexual maturations about six to seven weeks after hatching.

\subsection{EMBRYOGENESIS}

Parhyale was originally selected as a new crustacean model for comparative developmental studies (Rehm et al. 2009e). From the beginning, great effort has been invested in the detailed study of Parhyale embryogenesis that has been conveniently subdivided into well-defined stages based on morphological and molecular markers (Browne et al. 2005). Embryos have a number of useful properties for detailed microscopic inspection using brightfield or fluorescence imaging (Figure 16.3): the eggs are about $500 \mu \mathrm{m}$ long, the eggshell is transparent, and early development takes place on the egg surface, resulting in a nice contrast between the embryo and the underlying opaque yolk that later on gets sequestered inside the developing midgut.

\subsubsection{Early Cleavage Stages}

Early cleavages of the Parhyale zygote (Figure 16.3, 3h) follow a holoblastic, radial, determinate and stereotyped pattern (Gerberding et al. 2002). The first cleavage occurs

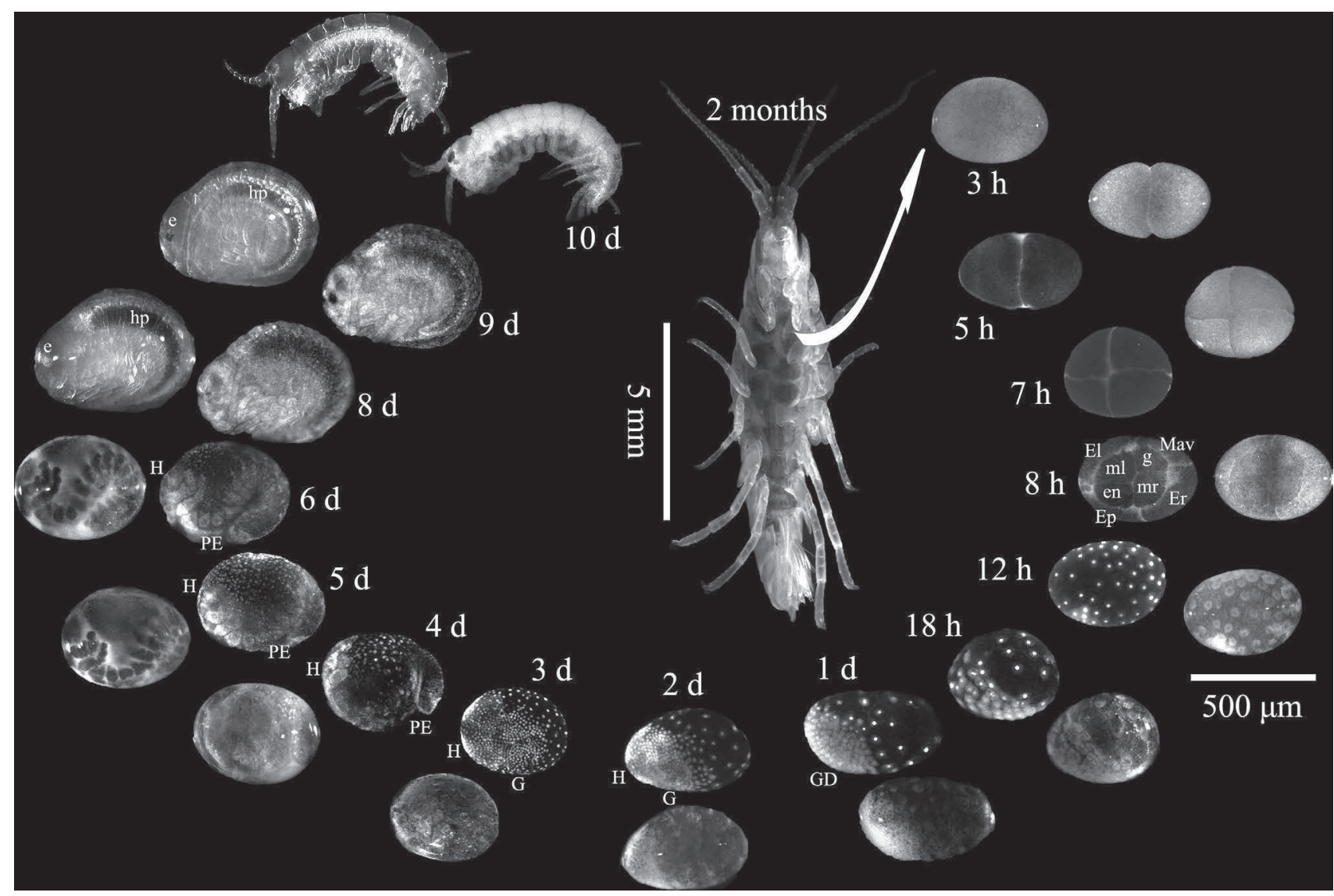

FIGURE 16.3 Parhyale hawaiensis embryogenesis. Brightfield images (aligned in the outer positions) and fluorescent images (aligned in the inner positions) of embryos at the indicated stages in hours (h) or days (d) after egg lay. Embryos can be removed from the marsupial pouch of anesthetized gravid females at any stage. The names of the macromeres and micromeres contributing to the different germ layers and the germ line are indicated in the eight-cell stage embryo $(8 \mathrm{~h})$. The juveniles that hatch from the eggs are miniature versions of the adults. All embryonic stages are shown to scale. Abbreviations: GD, germ disc; H, head; G, grid; PE, posterior end; hp, hepatopancreatic caecum; e, eye. 
about four hours after egg lay (AEL) at $26^{\circ} \mathrm{C}$ (Figure 16.3, $5 \mathrm{~h})$. It is perpendicular to the long axis of the egg and slightly unequal, and the fate of each of the two blastomeres is already restricted to the left or right side of the animal with regard to a large fraction of the ectoderm and mesoderm. The second cleavage is parallel to the long axis of the egg and also slightly unequal (Figure 16.3, 7h), while the third cleavage (perpendicular to the other two) is highly unequal, producing a stereotypical arrangement of four macromeres and four micromeres uniquely identifiable based on their relative position and size (Figure 16.3, 8h). Each of these blastomeres has an invariant fate restricted to a single germ layer already at this early developmental stage (Gerberding et al. 2002; Browne et al. 2005; Price and Patel 2008; Hannibal et al. 2012). Three macromeres, termed El, Er and Ep, give rise to the ectoderm: El and Er contribute the left and right head ectoderm and parts of the left and right thoracic ectoderm, respectively, while Ep contributes the remaining thoracic and abdominal ectoderm, as well as a distinct column of cells marking the ventral midline of the embryo and separating its left and right sides. The fourth macromere, termed Mav, generates the visceral and somatic head mesoderm. Two micromeres, called $\mathrm{mL}$ and $\mathrm{mr}$, form the left and right somatic trunk mesoderm, while the other two micromeres, called en and g, give rise to the endoderm and germ line, respectively. Despite these very early lineage restrictions, Parhyale embryos have the capacity to replace missing parts of the ectoderm and mesoderm after ablation of precursors during early development (Price et al. 2010). Similarly, although the germ line is normally specified in a cell-autonomous manner at the eight-cell stage (Extavour 2005; Ozhan-Kizil et al. 2009; Gupta and Extavour 2013), Parhyale has the astonishing flexibility to regenerate its germ line post-embryonically (presumably through reprogramming of somatic cells) after ablation of the $\mathrm{g}$ micromere (Modrell 2007; Kaczmarczyk 2014).

\subsubsection{Gastrulation and Germ Disc Formation}

Synchrony is gradually lost in later cleavages, and cells become yolk free as they extrude their yolk toward the center of the egg. The macromeres divide faster than the micromeres, forming a soccer ball-like embryo that consists of about 100 uniform cells around the egg surface at 12 hours AEL (Figure 16.3, 12h). Over the following 8 hours, gastrulation is effected by cell shape changes, neighbor exchange and cell migration (Figure 16.3, 18h) (Price and Patel 2008; Alwes et al. 2011; Chaw and Patel 2012). The group of Mav and $\mathrm{g}$ descendants (visible as a characteristic rosette) internalizes underneath a condensing epithelial monolayer formed by the El, Er and Ep descendants (ectoderm primordium), resulting in a multi-layered and bilaterally symmetric germ disc (embryo rudiment) at the anterior ventral side of the egg (Figure 16.3, 1d). The presumptive trunk somatic mesoderm ( $\mathrm{mL}$ and $\mathrm{mr}$ descendants) and endoderm (en descendants) precursors internalize at the periphery of the germ disc. A few cells that do not contribute to the initial ventral germ disc remain widely distributed around the dorsal egg surface. The descendants of these cells contribute later on to the growing embryo proper, as well as to the adjoining extra-embryonic region.

\subsubsection{Germ Band Extension and Segmentation}

The germ disc grows by cell proliferation and recruitment of new cells laterally and posteriorly. About two days AEL, embryonic cells start organizing into an anterior pair of head lobes followed by a grid-like array that will give rise to the rest of the germ band (Figure 16.3, 2d-3d and Figure 16.4a, b). The ectodermal cells in this grid exhibit an ordered arrangement in transverse rows (perpendicular to the ventral midline) and longitudinal columns (parallel to the ventral midline) (Figure 16.4). The formation and growth of the ectodermal grid occur with an anterior-toposterior progression, that is, the more anterior rows are formed first, and the more posterior rows are added sequentially at the posterior end of the grid (Figure 16.4b) (Browne et al. 2005). These rows will eventually give rise to most body units of Parhyale (called the post-naupliar region), and only the head region anterior to the mandibles (called the naupliar region) is formed from ectodermal cells outside the grid. Among all pancrustaceans and arthropods, this early patterning of the ectoderm by means of a highly ordered grid-like array of precursor cells is a unique common feature of Malacostracans (Dohle et al. 2003). Unlike most Malacostracans, though, that form this grid through the asymmetric repeated divisions of ectoderm stem cells called ectoteloblasts, amphipods like Parhyale lack ectoteloblasts and form the post-naupliar grid through the aforementioned progressive self-organization of scattered ectodermal cells into transverse rows of cells (Figure 16.4b).

Similar to Drosophila and the rest of the arthropods, the metameric organization of the early Parhyale embryo is parasegmental, with each transverse row of cells corresponding to one parasegment (Browne et al. 2005). Each row of cells undergoes two rounds of stereotyped and symmetric mitotic divisions, first producing a two-row and then a four-row parasegment (Figure 16.4c). These divisions are oriented parallel to the anterior-posterior axis, producing the ordered arrangement of daughter cells in well-defined longitudinal columns of cells. The geometric precision and invariance of the grid pattern enables to identify individual cells between the left and right side in each embryo and across embryos. A naming convention based on numbers and letters has been established by Prof. Wolfgang Dohle to indicate the position of cells in the one-, two- or fourrow parasegments along the anterior-posterior axis and in the columns along the dorsal-ventral axis (Figure 16.4b, c) (Dohle et al. 2003; Browne et al. 2005).

The regularity of the grid dissolves during the following divisions that are not strictly longitudinal but have a more complex, yet still invariant, pattern. At the tissue 

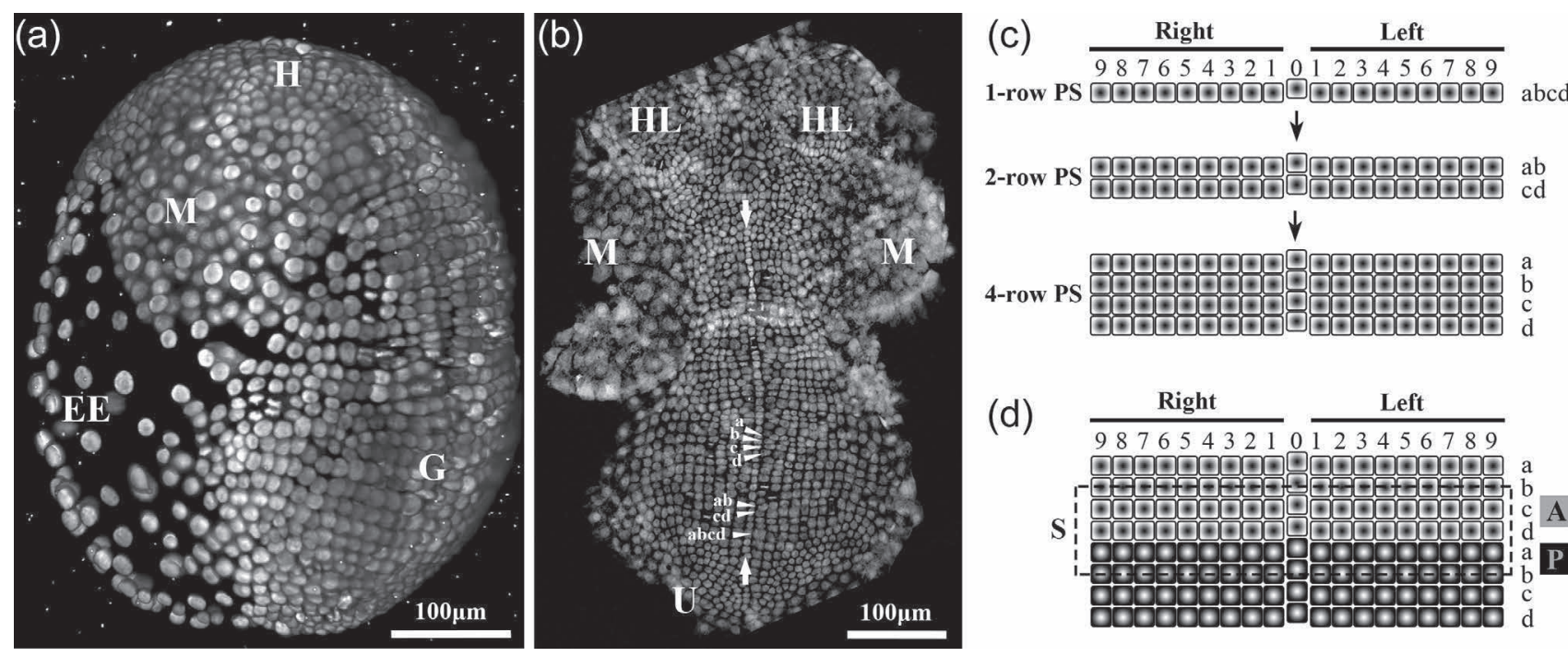

(d)

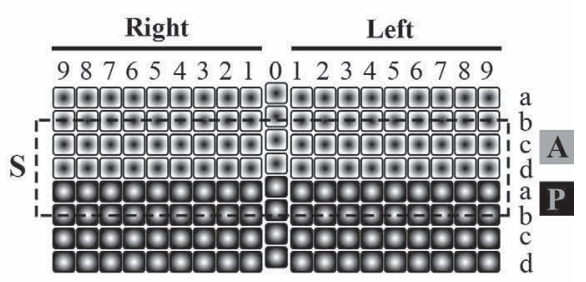

FIGURE 16.4 Parhyale hawaiensis ectoderm segmentation. (a) Right side of a live imaged Parhyale embryo with fluorescently labeled nuclei at the mid-germ band stage (anterior to the top and ventral to the right). Note the distinct organization and density of cells in the naupliar head region $(\mathrm{H})$, the post-naupliar grid $(\mathrm{G})$, the midgut primordium $(\mathrm{M})$ and the extra-embryonic region (EE). (b) Ventral view of a similar staged fixed embryo with stained nuclei. From anterior (top) to posterior (bottom), the embryo is organized into the bilateral pairs of head lobes (HL) and midgut primordia (M), the conspicuous column of ectodermal cells marking the ventral midline (flanked by arrows) and the ectodermal grid with the constellation of parasegments that have undergone two rounds of mitotic cell divisions (four-row parasegment indicated with a, b, c and d), one round of cell divisions (two-row parasegment indicated with ab and cd), no cell division (one-row parasegment indicated with abcd) and unorganized cells before they become arranged in rows (U). (c) Schematic representation and naming convention of grid cells: one-row-parasegment (top) with abcd cells; two-row-parasegment (middle) with anterior $\mathrm{ab}$ and posterior cd cells; and four-row-parasegment (bottom) with a, b, c and d cells. Mediolateral columns are indexed by numbers with 0 denoting the ventral midline and $1,2 \ldots n$ the more lateral columns based on their distance from the midline. (d) Schematic representation of segmental organization. Cells from two neighboring parasegments (indicated with different patterns) contribute to each morphological segment (bounded by a rectangular line). Each segment is compartmentalized into anterior (A) and posterior (P) compartment cells derived from the anterior and posterior parasegment, respectively. Segmental boundaries run between progenies of the $b$ cell rows.

level, transverse intersegmental furrows indicate the transition from the parasegmental to the segmental metameric organization of the embryo, and pairs of appendage buds start appearing ventrally, first in the anterior head segments and then more posteriorly (Figure 16.3, 4d). Like in other arthropods, each morphological segment and associated appendages are composed of cells from two neighboring parasegments without any cell mixing (Figure 16.4d): cells from the posterior rows of one parasegment contribute to the anterior compartment of the segment, while cells from the anterior rows of the following parasegment contribute to the posterior compartment of the segment (Browne et al. 2005; Wolff et al. 2018).

The mesoderm in Parhyale is derived from the $\mathrm{mL}$ and $\mathrm{mr}$ micromeres producing the left and right segmental mesoderm in the trunk, respectively, and the Mav macromere producing the head and visceral mesoderm (Gerberding et al. 2002; Price and Patel 2008; Vargas-Vila et al. 2010). The segmental trunk mesoderm develops in tight association with the overlying, growing ectodermal monolayer also with an anterior-to-posterior progression (Hannibal et al. 2012). In all Malacostracans, including Parhyale, the mesoderm in each trunk segment is formed from a row of eight founder cells, called mesoblasts, four in the left and four in the right hemisegment (Browne et al. 2005; Price and Patel 2008). The segmental rows of mesoblasts are the product of the asymmetric, repeated divisions of eight mesodermal stem cells, called mesoteloblasts, that are derived from the $\mathrm{mL}$ and $\mathrm{mr}$ lineages and are also uniquely identifiable based on their position and the use of a standardized nomenclature (Dohle et al. 2003). To summarize, axial elongation of the Parhyale germ band occurs by the sequential addition and division of new ectodermal and mesodermal rows. As the growing germ band reaches the posterior pole of the egg, it bends downward (Figure 16.3, 4d). During subsequent stages, the embryo acquires a comma shape, where the posterior abdominal trunk develops juxtaposed to the more anterior thoracic trunk.

\subsubsection{Organogenesis}

Ectodermal cells from the medial columns in the grid give rise to the nervous system and sternites, cells from the lateral columns give rise to the forming limbs and cells at the edge of the grid give rise to the dorsal body wall tergites (VargasVila et al. 2010; Wolff et al. 2018). As the comma-shaped embryo continues to grow, the posterior terminus (telson) projects anteriorly until it reaches the anterior thoracic region (Figure 16.3, 5d-6d). Concurrent with axial elongation, the 
lateral edges of the ectoderm expand dorsally and the forming tergites from the two body halves fuse along the dorsal midline completing dorsal closure. Starting from the anterior head region backward and sequentially bulging out in the thorax and the abdomen, a total of 19 pairs of appendages develop along the Parhyale body (Figure 16.3, 4d-6d). Appendages increase in size and elongate along their respective proximal-distal axes (Browne et al. 2005; Wolff et al. 2018). As detailed in the next sections, the elaboration of the proximal-distal axis varies between different appendage types in terms of their pattern, size and shape, resulting in a remarkable morphological diversity along the anterior-posterior axis. Appendage growth, morphogenesis and differentiation continue until the late stages of embryogenesis, when the fully formed appendages occupy almost half of the egg space before hatching (Figure 16.3, 8d-9d).

The naupliar (anterior head) and post-naupliar somatic mesoderm are separated early on as they derive from the Mav macromere and the $\mathrm{mL} / \mathrm{mr}$ micromeres at the eightcell stage, respectively (Figure 16.3, 8h) (Gerberding et al. 2002; Browne et al. 2005). The micromere-derived rows of four mesoteloblasts (labeled M1 to M4 medial-to-lateral) under each side the ectodermal grid generate the segmental mesodermal founders (mesoblasts labeled $\mathrm{m} 1$ to $\mathrm{m} 4$ ) in the posterior head (second maxillary segment) and the thoracic and abdominal segments. Similar to the ectodermal structures, patterning of mesoderm occurs with an anterior (earlier developing) to posterior (later developing) progression. The origin and first division of mesoblasts has been described in Parhyale (Price and Patel 2008). The contribution of these mesoblasts to the different muscle groups along the dorsal-ventral body axis has been studied in the closely related amphipod Orchestia cavimana and is only briefly summarized here (Hunnekuhl and Wolff 2012). Descendant cells from the medial-most $\mathrm{m} 1$ mesoblasts give rise to the ventromedian muscles, cells from the central $\mathrm{m} 2$ and $\mathrm{m} 3$ mesoblasts generate the extrinsic and intrinsic musculature of the appendages and cells from the $\mathrm{m} 3$ and $\mathrm{m} 4$ mesoblasts give rise to the dorsolateral trunk musculature and the heart (Figure 16.7e).

The Mav macromere gives rise to the head musculature of the antennae and the mandibular and first maxillary segments (Price and Patel 2008; Price et al. 2010; Hunnekuhl and Wolff 2012), as well as to the visceral mesoderm. After gastrulation, a subset of the Mav progeny migrates under the developing head segments and becomes partitioned into the differentiating head segments in a less studied manner. The majority of Mav progeny, together with the descendants from the en micromere, give rise to the midgut tube that will eventually spread over and encapsulate the central yolk mass (Gerberding et al. 2002). During the germ band stages, the midgut primordium becomes visible as a bilateral pair of discs under the head lobes (Figure 16.4a, b). The discs increase in size, forming a continuous ventral layer that expands dorsally and posteriorly under the ectoderm and mesoderm to cover the yolk (Gerberding et al. 2002). The midgut develops a number of blind tubes (caeca) that function in food digestion and absorption (Schmitz and Scherrey 1983). The most conspicuous pair of anterior caeca, called hepatopancreatic caeca, extend in synchrony through peristaltic contractions from the anterior end of the midgut until the posterior abdomen of the embryo (Browne et al. 2005). The hepatopancreatic caeca flank and extend parallel to the midgut that is visible along the dorsal side (Figure 16.3, 8d-9d). The Parhyale heart develops as a muscular tube along the dorsal thoracic region with three pairs of lateral inflow valves and an anterior outflow valve, and it can be observed while beating on top of the midgut (Kontarakis et al. 2011b). At around the same stage when the heart starts beating, the bilaterally symmetric compound eyes become visible in the head capsule as small white clusters, each with about three ommatidia (Figure 16.3, 8d). During the last two days of embryogenesis, the eyes become dark pigmented, and Parhyale hatch with about eight to nine pigmented ommatidia per eye (Figure 16.3, 9d-10d), but this number increases gradually to about 50 in older adults (Ramos et al. 2019).

The smallest micromere $g$ at the eight-cell stage is the source of germ line cells in the adult ovaries and testes (Figure 16.3, 8h) (Gerberding et al. 2002; Extavour 2005). There is strong evidence that germ cells in Parhyale are specified by a cell-autonomous mechanism (preformation) via the early asymmetric segregation of maternally provided germ line determinants (Extavour 2005; Modrell 2007; Gupta and Extavour 2013). The primordial germ cells (progeny of the $\mathrm{g}$ micromere) that have internalized and proliferated during the gastrulation and germ disc stages form a single medial cluster of about 15 cells under the posterior head ectoderm as the germ band elongates. During organogenesis stages, they split into two bilaterally opposed cell populations that migrate separately under the lateral ectoderm toward the dorsal side of the embryo (Extavour 2005; Browne et al. 2005). At the end of embryogenesis, when the eyes and the heart have formed, the primordial germ cells are aligned in two rows flanking the dorsal midline at the site of the future gonads (Extavour 2005).

\subsection{ANATOMY}

Parhyale displays the typical amphipod body plan that is laterally compressed and consists of a series of repeating segmental units along the anterior-posterior axis organized into three major tagmata: the head, the thorax and the abdomen (Figure 16.5a, b). The head (a.k.a. cephalon) is composed of six segments with five pairs of appendages. The most anterior limbless pre-antennal segment is followed by five segments bearing the first and second pair of antennae (An1 and An2; Figure 16.5a, b) and three pairs of medially fused gnathal appendages: the mandibles (Mn; Figure 16.5c) and the first and second maxillae (Mx1 and Mx2; Figure 16.5d). The thoracic region is composed of eight segments, each bearing a pair of jointed uniramous appendages (I-shaped limbs with a single proximal-distal axis) (Figure 16.5e-i). The abdominal region is composed of six segments, each 
bearing a pair of jointed biramous appendages (Y-shaped limbs with a bifurcated proximal-distal axis) (Figure 16.5J, $\mathrm{K})$. Each thoracic and abdominal appendage consists of a proximal part and a distal part (Boxshall 2004; Pavlopoulos and Wolff 2020). The proximal part, called a protopod, is composed of two appendage articles (a.k.a. podomeres or limb segments), namely the proximal coxa and the distal basis (Figure 16.5g). The existence of a third proximal-most podomere, the precoxa, has been also proposed recently (Bruce and Patel 2020). In uniramous thoracic appendages (Figure $16.5 \mathrm{e}-\mathrm{i}$ ), a single branch extends distally from the protopod called the endopod (or telopod). In abdominal biramous appendages (Figure 16.5j, k), two branches extend distally from the protopod called the endopod (inner branch) and exopod (outer branch). As detailed in the following, different types of appendages develop also a variable number of ventral and/or dorsal outgrowths from their protopod called endites and exites, respectively,

The first thoracic segment (T1) is fused to the head that is also referred to as the cephalothorax. The T1 appendages, called maxillipeds (T1/Mxp; Figure 16.5e), are jointed, and uniramous like the more posterior thoracic appendages. However, unlike the other thoracic appendages and similar to the more anterior maxillae, maxillipeds are reduced in size, are medially fused at their base and have two prominent endites on their proximal segments (Figure 16.5e). Maxillipeds and gnathal appendages are specialized for feeding and have a compact arrangement around the mouth region (Figure 16.5b). The thoracic region behind T1, known as the pereon, is composed of seven segments (T2 to T8), each with a pair of uniramous appendages (a.k.a. pereopods or thoracopods) that articulate independently on
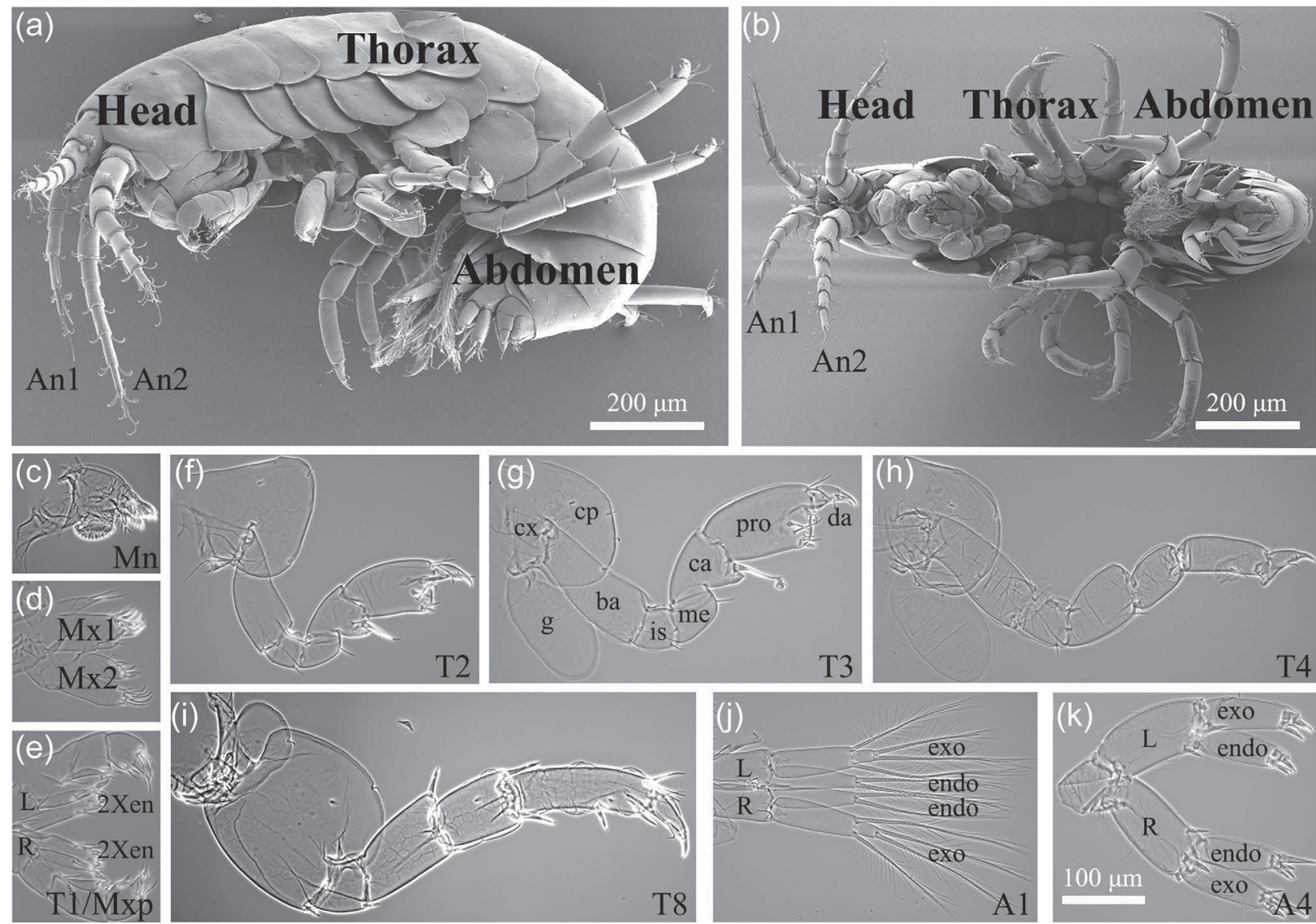

FIGURE 16.5 Appendage diversity in Parhyale hawaiensis. (a) Scanning electron micrograph of a Parhyale juvenile showing the different tagmata along the anterior-posterior body axis and the first and second pair of antennae (An1 and An2). Lateral view with anterior to the left and ventral to the bottom. (b) Similar to (a) from a ventral view. (c-k) Cuticle preparations of dissected appendages with their proximal side to left and their distal side to the right: (c) mandible (Mn); (d) Maxilla 1 (Mx1) and Maxilla 2 (Mx2); (e) bilateral pair of maxillipeds from the first thoracic segment (T1/Mxp) indicating the pair of endites (2Xen) on each side; (f) gnathopod from the second thoracic segment (T2); (g) gnathopod from the third thoracic segment (T3) indicating the seven segments, coxa (cx), basis (ba), ischium (is), merus (me), carpus (ca), propodus (pro) and dactylus (da), as well as the two exites, the coxal plate (cp) and the gill (g); (h) pereopod from the fourth thoracic segment (T4); (i) pereopod from the eighth thoracic segment (T8); (j) bilateral pair of pleopods from the first abdominal segment (A1) and (k) bilateral pair of uropods from the fourth abdominal segment (A4) indicating the endopod (endo) and exopod (exo) on each side. All appendages are shown to scale. 
each side (Figure 16.5f-i). From proximal to distal, each jointed pereopod is made of seven segments: two protopodal segments (coxa and basis) and five endopodal segments (ischium, merus, carpus, propodus and dactylus) (Figure 16.5g). The T2 and T3 segments bear subchelate (clawed) grasping appendages, called gnathopods (Figure 16.5f, g), that are used for defense, grooming and as precopulatory organs (the T2 gnathopods) by males to carry the females (Holmquist 1982). The post-embryonic enlargement of the propodus and dactylus exclusively in the male T3 gnathopod is the most striking sexually dimorphic character in Parhyale (Figure 16.2c, d). The remaining five pereonic segments T4 to T8 bear elongated walking appendages (Figure $16.5 \mathrm{~h}, \mathrm{i})$. Importantly, the opposite orientation between the T4/T5 pereopods that extend anteriorly and the T6/T7/T8 pereopods that extend posteriorly (Figure $16.5 \mathrm{a}, \mathrm{b}$ ) is what gives the group its name (from Greek words $\alpha \mu \varphi i$ [amphi $=$ both ways] and $\pi \delta ́ \delta l$ [podi $=$ limb]). Besides their distinct function, podomere morphology and orientation, the T2-T8 pereopods are also distinguished by the presence or absence and the shape of exites attached on their protopodal coxa. Protective coxal plates of variable size and shapes are present on all pereopods, while respiratory gills are present on T3 to T7 appendages (Figure 16.5g). In the case of adult females, special endites (oostegites) forming the marsupium are attached on the pereopods T2 to T5.

The abdominal (pleonic) segments A1 to A6 develop two types of paired biramous appendages: pleopods on A1 to A3 (Figure 16.5j) and uropods on A4 to A6 (Figure 16.5k). Each of these biramous limbs has similar endopodal and exopodal branches. The A1-A3 pleopods (a.k.a. swimmerets) are highly setose and are coupled together for swimming and moving water over the thoracic gills. The A4-A6 uropods are thickened and spiky appendages used for jumping. The most posterior terminal structure is the telson, which is a small flap over the anus attached to segment A6. Overall, the morphological and functional specialization of body parts and associated appendages has been one of the main reasons for putting Parhyale forward as an attractive model organism for molecular, cellular, developmental and evolutionary studies described in Section 16.8.

Much less work has been invested in Parhyale to study the development, anatomy and physiology of the nervous system compared to other crustaceans (Wiese 2002).
Parhyale neuroanatomy was recently described using a combination of histological, immuno-histochemical, optical and X-ray tomography methods (Wittfoth et al. 2019). The central nervous system consists of the brain and the ventral nerve cord. The ventral nerve cord is composed of the subesophageal ganglion, seven segmental ganglia of the pereon, three segmental ganglia of the pleosome and one fused ganglion of the urosome. The brain lies between the compound eyes in the dorsal part of the head capsule with its three neuromeres, the protocerebrum, deutocerebrum and tritocerebrum lining up from dorsal to ventral. The protocerebrum is equipped with the optic neuropils, the deutocerebrum with the antenna 1 neuropil and the olfactory lobe and the tritocerebrum with the antenna 2 neuropil. The three optic neuropils, the lamina, medulla and lobula, are in close proximity with each other, but only the lamina connects to the photoreceptors of the ommatidia in the compound eye (Wittfoth et al. 2019; Ramos et al. 2019). The architecture and neural connectivity of the Parhyale visual system have diverged from the typical organization exhibited by other malacostracan crustaceans and are associated with a shift to low spatial resolution and simple visual tasks (Ramos et al. 2019).

\subsection{GENOMIC DATA}

For many years, the high cost of next-generation sequencing technologies and the big size of malacostracan crustacean genomes have been prohibitive for amphipod genomics. Thanks to the decreasing sequencing costs, this limitation was overcome during the last five years, first with the sequencing, de novo assembly and annotation of the Parhyale genome in 2016, followed more recently by genome assemblies of variable quality for the amphipods Hyalella azteca, Trinorchestia longiramous, Platorchestia hallaensis, Orchestia grillus and Gammarus roeselii (Table 16.1) (Poynton et al. 2018; Patra et al. 2020a, 2020b; Cormier et al. 2021).

The Parhyale genome resembles and even exceeds in many respects the complexity of the human genome. The genome consists of 23 pairs of chromosomes $(2 n=46$; Figure 16.6a), and its size is estimated at $3.6 \mathrm{~Gb}$. The huge genome size is associated with an expansion in repetitive and intronic sequences and exhibits very high levels of

\section{TABLE 16.1}

\section{Sequenced Amphipod Genomes}

\begin{tabular}{|c|c|c|c|c|}
\hline Species & $\begin{array}{l}\text { Size } \\
(G b)\end{array}$ & $\begin{array}{l}\text { No. of } \\
\text { Scaffolds }\end{array}$ & $\begin{array}{c}\text { Scaffold N50 } \\
(\mathrm{Kb})\end{array}$ & NCBI Link \\
\hline Parhyale hawaiensis & 2.75 & 278,189 & 20,229 & www.ncbi.nlm.nih.gov/assembly/GCA_001587735.2 \\
\hline Hyalella azteca & 0.55 & 18,000 & 215 & www.ncbi.nlm.nih.gov/assembly/GCA_000764305.3 \\
\hline Trinorchestia longiramus & 0.89 & 30,897 & 120 & www.ncbi.nlm.nih.gov/assembly/GCA_006783055.1 \\
\hline Platorchestia hallaensis & 1.18 & 39,873 & 87 & www.ncbi.nlm.nih.gov/assembly/GCA_014220935.1 \\
\hline Orchestia grillus & 0.81 & 143,039 & 17 & www.ncbi.nlm.nih.gov/assembly/GCA_014899125.1 \\
\hline Gammarus roeselii & 3.2 & $1,130,582$ & 4.8 & www.ncbi.nlm.nih.gov/assembly/GCA_016164225.1 \\
\hline
\end{tabular}


heterozygosity and polymorphism (Kao et al. 2016). This published version of the genome called Phaw_3.0 (GenBank Accession number GCA_001587735.1) was sequenced to about $115 x$ coverage from variable-sized shotgun and matepair Illumina libraries prepared from a single adult male from the Chicago-F iso-female line. The latest version of the genome, called Phaw_5.0 (GenBank Accession number GCA_001587735.2), was assembled from these reads supplemented with extra sequences to about 150x coverage from Dovetail Genomics proximity ligation libraries, which were generated from both in vitro reconstituted chromatin (socalled Chicago libraries prepared from the same genomic DNA used for the Illumina libraries) and native chromatin (so-called Hi-C libraries prepared from another adult male belonging to the same iso-female line) (Putnam et al. 2016). The resulting assembly with the Dovetail HiRise scaffolding pipeline has a total length of $2.75 \mathrm{~Gb}$ and consists of 278,189 scaffolds with an N50 of about $20 \mathrm{Mb}$ and an L50 of 42 scaffolds (Table 16.1).

The availability of the high-quality reference genome has boosted functional studies of coding and non-coding sequences in Parhyale, as well as comparative genomic studies with other amphipods and animal taxa in general (Figure 16.6b-d) (Kao et al. 2016). The genome is accompanied and supported by an increasing number of other genome-wide resources, such as sex, stage and tissue-specific transcriptomes and proteomes, sequenced BAC clones, epigenetic marks and chromatin accessibility profiles (Parchem et al. 2010; Zeng et al. 2011; Zeng and Extavour 2012; Blythe et al. 2012; Nestorov et al. 2013; Trapp et al. 2016; Kao et al. 2016; Hunt et al. 2019; Artal et al. 2020). Annotation of the genome based on assembled Parhyale transcriptomes, homology with other model organisms and $a b$ initio predictions has resulted in more than 28,000 protein-coding gene models (Kao et al. 2016). Most likely, this number is an overestimate of the actual protein-coding gene number (due to fragmented genes, different alleles or isoforms sorted as separate entries) that will be dropping as more genomewide datasets become available. A much larger number of assembled transcripts with small predicted open reading frames have been classified as non-coding, bringing the total number of transcripts in the Parhyale transcriptome to over 280,000. These annotated non-coding RNAs include rRNAs, tRNAs, snRNAs, snoRNAs, eRNAs, ribozymes and lncRNAs, as well as non-coding RNAs and associated proteins of the siRNA, piRNA and miRNA pathways (Kao et al. 2016).

All common signaling pathways have been annotated in Parhyale, including components of the Wnt, TGF- $\beta$, Notch and FGF pathways. The genome encodes more than 1,100 transcription factors belonging to all major families, such as zinc-finger, helix-loop-helix, helix-turn-helix, ETS, Forkhead, homeobox-containing genes and others (Kao et al. 2016). As will be discussed in Section 16.8, particular efforts have been devoted to the analysis of transcription factors encoded by the nine Parhyale Hox genes that are organized in a cluster spanning more than $2 \mathrm{Mb}$ (Serano et al. 2016; Kao et al. 2016; Pavlopoulos and Wolff 2020). Special attention has been given to the annotation of innate immunity genes and pathways as a resource for immunological studies relevant for crustacean food crop species (Kao et al. 2016; Lai and Aboobaker 2017). Another important discovery that emerged from comparative genomic and transcriptomic analyses is
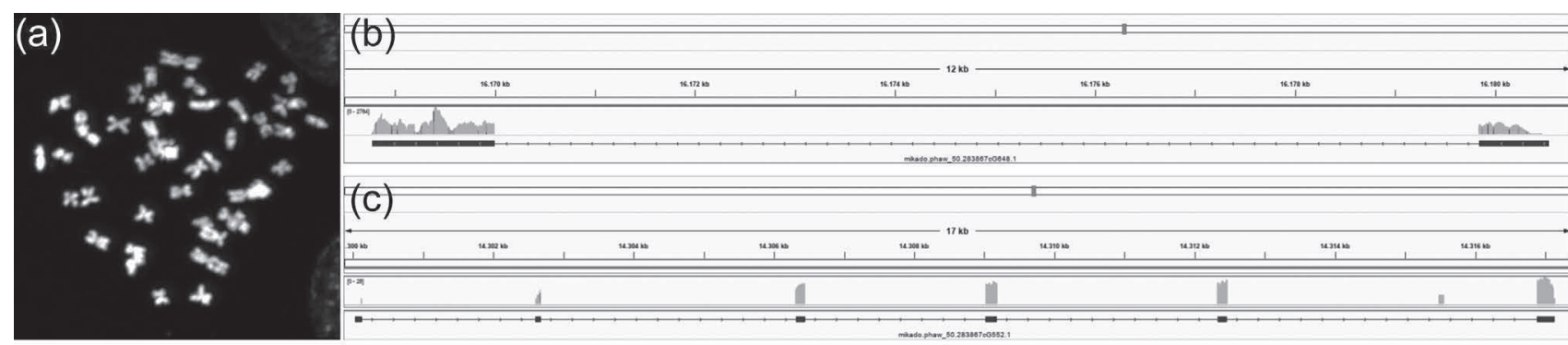

(d) Trinorchestia longiramus

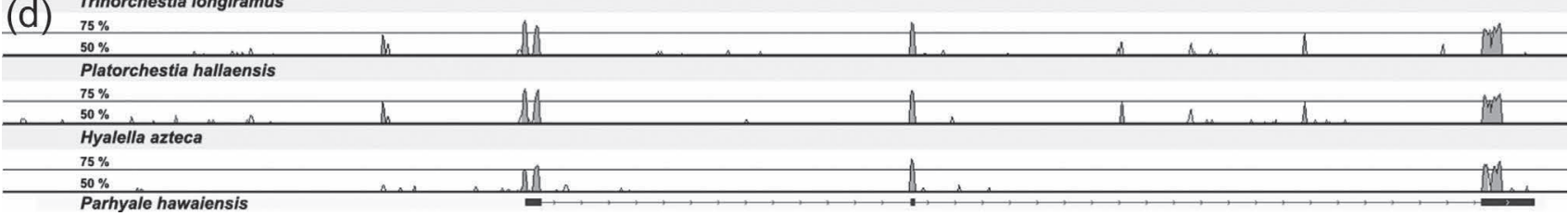

FIGURE 16.6 Parhyale genome-wide resources. (a) The karyotype of Parhyale consisting of 46 chromosomes. (b-c) Two examples of the Parhyale genome visualized with the Integrative Genomics Viewer. In each case, the small gray box at the top indicates the zoomedin region of the scaffold that is displayed in detail. The span and the ruler underneath indicate the number of bases in display. Gene models are shown at the bottom, with filled boxes representing exons and thin lines representing introns. The track with the histograms above each gene model indicates the mapped reads from a transcriptomic data set. (d) Vista plots showing pairwise sequence comparisons for one locus between Parhyale and each of three other available amphipod genomes. High sequence similarity (above 50\% indicated with histograms) is observed in exonic sequences (filled boxes) and in some non-exonic regions corresponding to putative conserved cisregulatory sequences. ([b-c] Robinson et al. 2011.) 


\section{TABLE 16.2}

\section{Experimental Resources for Parhyale Research}

Embryological manipulations

Gene expression analysis

Transgenesis

Gene trapping

Gain-of-function studies

Loss-of-function studies

Genome editing

Imaging

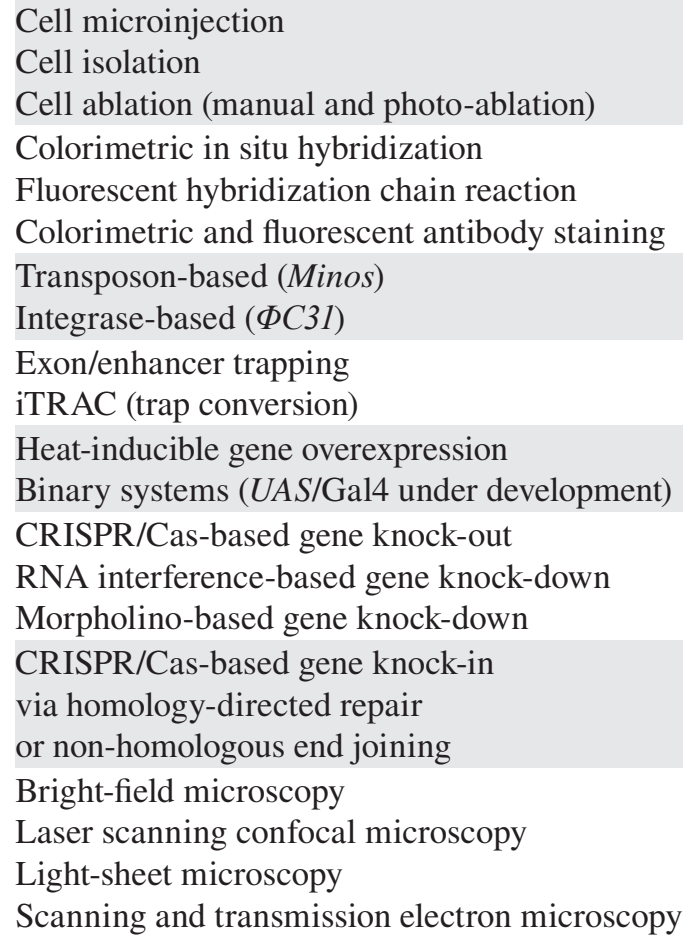

that the genomes of Parhyale and other marine crustaceans encode the full complement of enzymes required to extract metabolizable sugars from a lignocellulosic diet in the absence of symbiotic microorganisms (King et al. 2010; Kao et al. 2016). The capacity of marine crustaceans and Parhyale for autonomous wood digestion allows to harness the natural diversity in lignocellulose depolymerization mechanisms for green biofuel production and other biotechnological applications (Kern et al. 2013; Cragg et al. 2015; Chang and Lai 2018).

\subsection{FUNCTIONAL APPROACHES: TOOLS FOR MOLECULAR AND CELLULAR ANALYSES}

Parhyale has a set of biological and technical attributes that make it an attractive and powerful system for embryological and developmental genetic research (Rehm et al. 2009e; Stamataki and Pavlopoulos 2016). It is cultured easily and inexpensively in large numbers in the laboratory, it has a relatively fast life cycle, and a large number of transparent embryos are accessible at all stages of development and throughout the year. The arsenal of Parhyale tools and resources (Table 16.2) was built on a detailed description of the early embryo fate map and a comprehensive staging system for embryonic development (Gerberding et al. 2002; Browne et al. 2005). Robust protocols have been established for embryo dissection and fixation, as well as analysis of gene expression by colorimetric and fluorescent in situ hybridizations and immunohistochemistry (Rehm et al. 2009b, 2009c, 2009a; Choi et al. 2018). Likewise, a number of studies have demonstrated the amenability of Parhyale embryos to diverse embryological manipulations, including cell microinjection, labeling with lineage tracers, manual or photo-ablation, isolation and combinations thereof (Gerberding et al. 2002; Rehm et al. 2009d; Extavour 2005; Price et al. 2010; Hannibal et al. 2012; Nast and Extavour 2014; Kontarakis and Pavlopoulos 2014).

To facilitate functional genetic and genomic research in Parhyale, several efforts have been invested in developing an experimental toolkit of increasing scope and sophistication (Figure 16.7). Transgenesis in Parhyale was first achieved using the Minos transposon from Drosophila hydei that is active in a large variety of animal models (Pavlopoulos and Averof 2005; Pavlopoulos et al. 2007). Engineered transposons consist of the terminal inverted repeats of the Minos transposon flanking a transformation marker gene for detection of transgenic individuals (Figure 16.7d) and the desired transgene that is being tested (Figure 16.7e). Engineered transposons are mobilized from plasmids co-injected with a transient source of the Minos transposase into fertilized eggs and get randomly inserted into the genome (Kontarakis and Pavlopoulos 2014). Transposon-based transgenesis is used routinely to insert exogenous DNA into Parhyale (Pavlopoulos and Averof 2005; Pavlopoulos et al. 2009; Ramos et al. 2019) but has been also employed in unbiased gene trapping screens on a small scale to identify new gene functions (Kontarakis et al. 2011b). The characterization of 
endogenous heat-inducible promoters further allowed the development of conditional gene misexpression systems for gain-of-function studies in Parhyale (Pavlopoulos et al. 2009). The transgenic approaches in Parhyale have been expanded with the use of the bacteriophage $\Phi C 31$ integrase for the site-specific insertion of transgenes into the genome (Kontarakis et al. 2011b). In addition, the combination of transposon with integrase-based transformation systems can increase the versatility of genetic manipulations in Parhyale, such as the redeployment of gene traps for creating cell and tissue markers for microscopy, drivers for ectopic gene expression, landing sites for inserting large cargos and other applications (Kontarakis et al. 2011a, 2011b).

Complementary loss-of-function studies in Parhyale were first conducted using RNA interference and morpholinomediated gene knock-down approaches (Liubicich et al. 2009; Ozhan-Kizil et al. 2009). However, gene knock-down suffered a number of limitations, such as the incomplete and transient reduction in gene function. This problem was solved by employing targeted genome editing approaches based on the clustered regularly interspaced short palindromic repeats (CRISPR)/CRISPR-associated (Cas) system (Figure 16.7ac). For reasons explained in the following, complete null phenotypes can be obtained with very high efficiency using CRISPR/Cas-based gene knock-out in Parhyale (Martin et al. 2016; Kao et al. 2016; Clark-Hachtel and Tomoyasu 2020; Bruce and Patel 2020). Moreover, the CRISPR/Cas system has been adapted to generate live fluorescent reporters of gene expression (Figure 16.7f) using both homologydependent and homology-independent knock-in approaches in Parhyale (Serano et al. 2016; Kao et al. 2016).

It should be stressed that the effects of all aforementioned functional genetic manipulations are routinely analyzed first in treated embryos (in the G0 generation) and subsequently confirmed through the study of established transgenic or mutant lines (in the G1 or G2 generations) (Kontarakis and Pavlopoulos 2014; Kao et al. 2016). The early accessibility to fertilized eggs in Parhyale, together with their complete cleavage mode and slow tempo of development, results in high transgenesis rates and high CRISPR/Cas-mediated mutagenesis efficiencies in treated G0 embryos that exhibit very low levels of mosaicism and carry the genetic alterations both in their soma and in their germ line (Pavlopoulos and Averof 2005; Pavlopoulos et al. 2009; Martin et al. 2016; Kao et al. 2016; Clark-Hachtel and Tomoyasu 2020; Bruce and Patel 2020). Furthermore, the early and stereotyped lineage restrictions in the Parhyale embryo allow the comparison between the wildtype and the genetically altered conditions in the same embryo (Figure 16.7a)(Pavlopoulos and Averof 2005; Pavlopoulos et al. 2009; Martin et al. 2016), as well as the targeting of specific
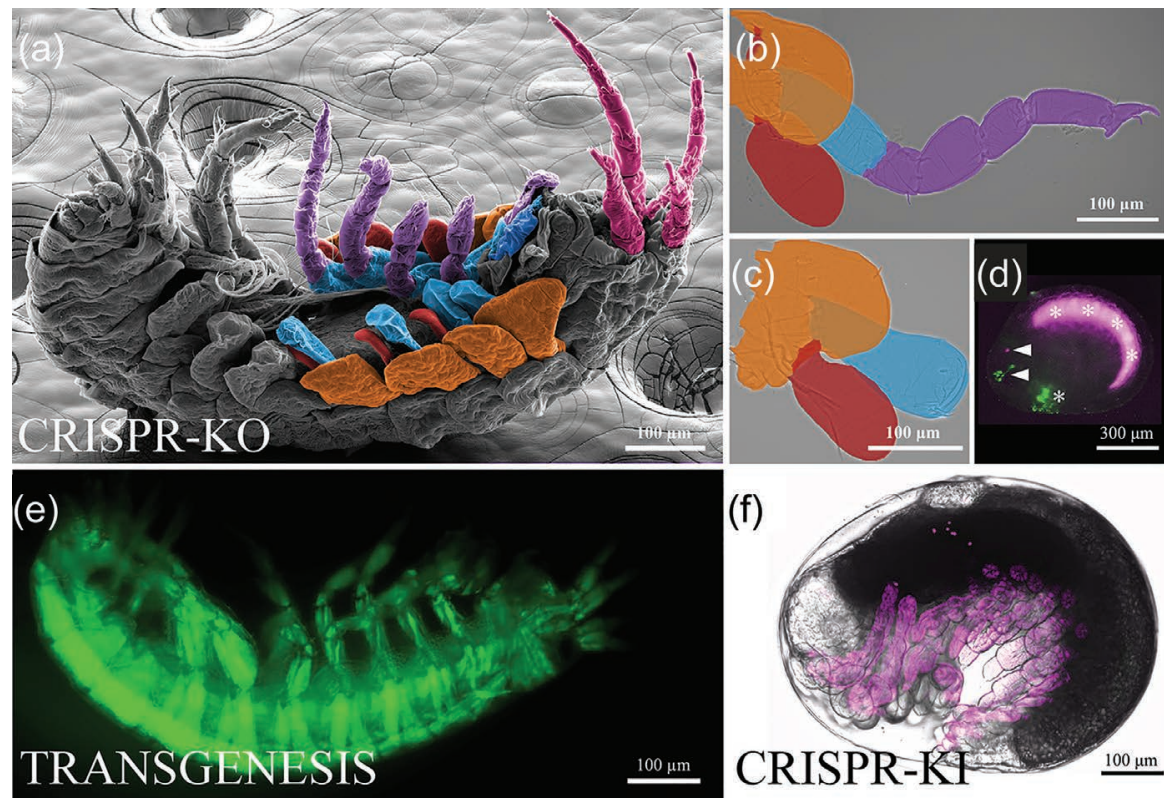

FIGURE 16.7 Functional approaches in Parhyale. (a) Phenotypic example of a CRISPR-based gene knock-out (CRISPR-KO) experiment. The image shows a scanning electron micrograph of a mosaic Parhyale juvenile with wild-type appendages on its right side and truncated appendages on its left side that are mutant for the limb patterning gene Distal-less $(\mathrm{Dll})$. Lateral view with anterior to the right and ventral to the top. (b) Cuticle preparation of a wild-type and (c) a mutant thoracic T4 appendage after CRISPR-based Dll knock-out. The proximal side is to the left and the distal side to the right. Color masks in panels (a) to (c) indicate the distal appendage structures (magenta) that are missing after Dll knock-out, as well as the proximal appendage structures (coxal plates in orange, gills in red and basis in cyan) that are not affected. (d) Transgenic late-stage Parhyale embryo expressing two different fluorescent transgenesis markers in the head region (arrowheads): a PhOpsinl-driven expression in the compound eye shown in green and a $3 x P 3$-driven expression more dorsally, shown in magenta. Asterisks indicate non-specific autofluorescence detected in the gnathal appendages (green) and in the gut (magenta). Lateral view with anterior to the left and ventral to the bottom. (e) Transgenic Parhyale juvenile, oriented as in (a), expressing a muscle-specific fluorescent reporter construct shown in green. (f) CRISPR-mediated knock-in (CRISPR-KI) of a construct in the Dll locus driving expression of a fluorescent reporter in the appendages (shown in magenta) merged with the corresponding brightfield image. ([d] Ramos et al. 2019; Pavlopoulos and Averof 2005.) 
lineages for labeling or ablation (Price et al. 2010; Alwes et al. 2011; Hannibal et al. 2012; Konstantinides and Averof 2014). All these features are very useful for experimentation in Parhyale, because they provide fast and reliable information about gene expression, regulation and function months before stable lines are available for analysis.

Parhyale is not only a genetically tractable but also an optically tractable experimental model, which is ideal to make the connection between the molecular and cellular basis of development. Light and electron microscopy analyses of fixed specimens have been used widely to characterize wild-type and mutant phenotypes in detail (Pavlopoulos et al. 2009; Serano et al. 2016; Martin et al. 2016; Ramos et al. 2019; Clark-Hachtel and Tomoyasu 2020; Bruce and Patel 2020). The increasing collection of genetic tools and transgenic lines for imaging, in combination with the transparency and low autofluorescence of embryos, have enabled the implementation of live microscopic inspections of cellular dynamics with exceptional spatial and temporal resolution. Different microscopy modalities, including bright-field, confocal and multi-view light-sheet microscopy, have been adapted successfully to image embryonic and post-embryonic processes over several days of development, such as Parhyale gastrulation and germ band formation, appendage development and regeneration (Price and Patel 2008; Alwes et al. 2011; Chaw and Patel 2012; Hannibal et al. 2012; Alwes et al. 2016; Wolff et al. 2018). Last but not least, thanks to a very productive collaboration between biologists, microscopists and computer scientists, a suite of sophisticated and open-source software is available for the visualization of image datasets, the manual and automated tracking of cells and the reconstruction and editing of cell lineages to understand the cellular behaviors contributing to tissue and organ development in Parhyale (Wolff et al. 2018; Salvador-Martínez et al. 2020; Sugawara et al. 2021).

\subsection{CHALLENGING QUESTIONS BOTH IN ACADEMIC AND APPLIED RESEARCH}

Parhyale lends itself to address several longstanding questions and problems in modern biological and biomedical research (Stamataki and Pavlopoulos 2016). Based on its phylogenetic position and its technical and biological attributes, it has increased the breadth and depth of comparative developmental studies with other pancrustacean, arthropod and animal groups. As a malacostracan crustacean, it is also closely related to shrimps, crabs and lobsters that have attracted research interest as commercially and nutritionally important crop species.

\subsubsection{Developmental Basis of Morphological Evolution}

Research in Parhyale was inspired by and has greatly contributed toward our understanding of the developmental mechanisms driving body plan evolution and specialization of body parts. Crustaceans exhibit a tremendous morphological diversity observed both within and between species. Seminal studies in crustaceans were among the first to implicate changes in the expression of Hox genes with the evolution of animal body plans and the diversification of developing appendages (Averof and Akam 1995; Averof and Patel 1997). Although expression studies of Hox genes have been carried out in all major crustacean lineages, the most comprehensive analysis of all nine Hox genes has been carried out in Parhyale, where they exhibit both spatial and temporal collinearity (Serano et al. 2016). Hox expression domains correspond to the subdivision of the body into morphologically and functionally distinct regions and correlate with the development of distinct appendages types. Importantly, systematic loss-of-function and gain-of-function studies of Hox genes in Parhyale have provided compelling evidence for the causal association between Hox genes and crustacean segmental organization and appendage diversification (Pavlopoulos et al. 2009; Liubicich et al. 2009; Martin et al. 2016). The homeotic transformations produced in these functional studies were recapitulating in Parhyale macroevolutionary changes observed in the body organization of other crustacean lineages, like the repeated evolution of feeding maxillipeds from locomotory appendages in the anterior thorax of many crustacean lineages or the change in the relative number of abdominal pleopods and uropods between malacostracan lineages (Averof et al. 2010; Martin et al. 2016; Pavlopoulos and Wolff 2020).

Along similar lines, expression and functional studies of developmental patterning genes in Parhyale have enabled to test century-old hypotheses about the homology and evolutionary novelty of arthropod appendages (McKenna et al. 2021). Considering that winged insects evolved from wingless crustaceans, different theories have been proposed to explain the origin of insect wings (Clark-Hachtel and Tomoyasu 2016): they are novel lateral outgrowths from the dorsal body wall (tergal origin or paranotal hypothesis), or they evolved from the exites of proximal leg segments (pleural origin hypothesis). By comparing the expression patterns and the loss-of-function phenotypes of leg, wing and body wall patterning genes between insects and Parhyale, it was proposed that the proximal exite-bearing leg segments present in the common ancestor of insects and crustaceans were incorporated into the insect body wall, giving rise to the insect wings (Clark-Hachtel and Tomoyasu 2020; Bruce and Patel 2020). Thus, these elegant studies in Parhyale have provided a fresh and unified model in favor of the evolution of insect wings from a pre-existing structure in their crustacean ancestor. A similar framework has been adopted to homologize pancrustacean, myriapod and chelicerate appendages, suggesting an eight-segment ground plan for the arthropod leg (Bruce 2021).

\subsubsection{Molecular and Cellular Basis of DeVelopment}

One of the biggest challenges in developmental biology is to understand how the genomic information encodes the morphogenetic cell behaviors, like cell proliferation and death, cell shape changes and cell movements, that produce the characteristic size and shape of developing tissues and organs 
in multicellular organisms (Heisenberg and Bellaïche 2013; Wan et al. 2019). The optical properties of the Parhyale egg and the embryonic development of its appendages as direct outgrowths from the body wall have enabled to advance beyond a gene-centric view of development and start integrating the molecular with the cellular aspects of appendage formation. In a tour-de-force study that involved advanced light-sheet fluorescence microscopy and image analysis tools, the complete lineage of developing Parhyale limbs was reconstructed with single-cell resolution (Wolff et al. 2018). The spatial coordinates for all constituent cells, their temporal dynamics and mother-daughter relationships were then analyzed to shed light on the cellular mechanisms driving appendage outgrowth, elongation and segmentation. These analyses revealed the cellular architecture and patterned cell activities operating at different stages of appendage development that were then correlated with the expression patterns of candidate patterning genes known from limb studies in Drosophila (Wolff et al. 2018). Interestingly, some of these cellular events were similar, but some were distinct compared to the textbook Drosophila paradigm, motivating future experiments to understand the conservation and divergence of appendage patterning mechanism during pancrustacean and arthropod evolution (Pavlopoulos and Wolff 2020).

In a broader perspective, all recent technical breakthroughs in Parhyale research provide the opportunity to study gene expression and function in the context of singlecell-resolution fate maps, both under wild-type and under genetically perturbed conditions. These multidisciplinary approaches will be employed by the community to advance our knowledge on longstanding questions in developmental biology, such as the identity and function of cell fate determinants (Nestorov et al. 2013; Gupta and Extavour 2013), the molecular and cellular mechanisms underlying embryo formation and healing (Alwes et al. 2011; Chaw and Patel 2012), the relative contributions of cell history and cell communication in development (Price et al. 2010; Hannibal et al. 2012) and the allometric growth of serially homologous appendages (Pavlopoulos et al. 2009; Martin et al. 2016).

\subsubsection{Molecular and Cellular Basis of Regeneration}

Besides studying embryonic development, Parhyale has emerged as an attractive model system for regenerative studies, as it has the capacity to replace lost tissues and entire body parts post-embryonically (Grillo et al. 2016). It has been demonstrated that Parhyale has the ability to regenerate missing limbs after amputation (Kontarakis et al. 2011b) and its germ line after ablation of the $\mathrm{g}$ micromere (Modrell 2007; Kaczmarczyk 2014). In principle, new cells for regeneration can be produced from the activation of pluripotent or lineage-restricted stem cells, as well as the de-differentiation or trans-differentiation of differentiated cells (Tanaka and Reddien 2011). Thanks to the early lineage restrictions in the Parhyale embryo, it has been possible to label and identify the source cells and examine their regenerative potential during regrowth of limbs (Konstantinides and Averof 2014). The sources for the new cells are restricted by their lineage and proximity to the regenerating appendage: the ectodermal and mesodermal lineages make distinct contributions to ectoderm-derived tissues (epidermis and neurons) and mesoderm-derived tissues (muscles and blood cells), respectively. Importantly, the availability of cell-specific markers led to the major discovery of invertebrate muscle stem cells in Parhyale that, similar to satellite cells in vertebrates, serve as progenitors for muscle repair during limb regeneration (Konstantinides and Averof 2014). It has been also possible to trace cell behaviors through live imaging of appendage regeneration in Parhyale with high resolution and over several days after amputation (Alwes et al. 2016). For example, the epidermis of the new limb is not formed by specialized stem cells but by the cell proliferation and redifferentiation of existing epidermal cells. Overall, crustaceans have a long history in regenerative research, albeit at the physiological and anatomical level. The addition of Parhyale as a new genetically and optically tractable regenerative model has opened new possibilities to dissect the molecular and cellular mechanisms that can be redeployed during its lifetime to replace missing limbs, germ cells and possibly other structures.

\subsubsection{New Research Directions}

We will conclude this chapter with some more exciting new research avenues that, like regeneration, were not conceivable when Parhyale was first introduced in the laboratory but have the potential to make big contributions to both basic and applied fields of research. The first steps have been taken already in establishing Parhyale as a model in the fields of chronobiology and ecotoxicology (Hunt et al. 2019; Artal et al. 2018, 2020; Diehl et al. 2021). Studies of the Parhyale innate immunity have been also proposed for disease control in crustacean aquaculture through a better understanding of infectious pathogens and host defense mechanisms (Kao et al. 2016; Lai and Aboobaker 2017). Last but not least, studies of lignocellulose digestion in Parhyale can offer novel insights into the ecologically important and understudied mechanisms of wood recycling in marine environments and can unleash their significant potential for biotechnological applications (Cragg et al. 2015; Kao et al. 2016; Chang and Lai 2018).

\section{ACKNOWLEDGMENTS}

This chapter was prepared amid the most challenging conditions imposed by the COVID-19 pandemic. It was only completed thanks to the unceasing patience and encouragement of our editors, Dr. Agnès Boutet and Dr. Bernd Schierwater, to whom we are deeply indebted. We would also like to thank Dr. Carsten Wolff and Suyash Kumar for providing the images in Figures 16.6a and 16.7a, and Dr. Evangelia Stamataki for comments on the manuscript. John Rallis and Gentian Kapai were supported by Fondation Santé graduate studentships and Anastasios Pavlopoulos by IMBB-FORTH intramural funds. 


\section{BIBLIOGRAPHY}

Alegretti, L., de Aragão Umbuzeiro, G., and M.N. Flynn. 2016. "Population Dynamics of Parhyale hawaiensis (Dana, 1853) (Amphipoda: Hyalidae) Associated with an Intertidal Algal Belt in Southeastern Brazil.” Journal of Crustacean Biology 36 (6): 785-791. doi:10.1163/1937240X-00002480.

Alwes, F., Enjolras, C., and M. Averof. 2016. "Live Imaging Reveals the Progenitors and Cell Dynamics of Limb Regeneration." ELife 5. doi:10.7554/eLife.19766.

Alwes, F., Hinchen, B., and C.G. Extavour. 2011. "Patterns of Cell Lineage, Movement, and Migration from Germ Layer Specification to Gastrulation in the Amphipod Crustacean Parhyale hawaiensis." Developmental Biology 359 (1): 110 123. doi:10.1016/j.ydbio.2011.07.029.

Artal, M.C., Dos Santos, A., Henry, T.B., and G. de Aragão Umbuzeiro. 2018. "Development of an Acute Toxicity Test with the Tropical Marine Amphipod Parhyale hawaiensis." Ecotoxicology (London, England) 27 (2): 103-108. doi:10.1007/s10646-017-1875-3.

Artal, M.C., Pereira, K.D., Luchessi, A.D., Okura, V.K., Henry, T.B., Marques-Souza, H., and G. de Aragão Umbuzeiro. 2020. "Transcriptome Analysis in Parhyale hawaiensis Reveal Sex-Specific Responses to AgNP and AgCl Exposure." Environmental Pollution (Barking, Essex: 1987) 260 (May): 113963. doi:10.1016/j.envpol.2020.113963.

Averof, M., and M. Akam. 1995. "Hox Genes and the Diversification of Insect and Crustacean Body Plans.” Nature 376 (6539): 420-423. doi:10.1038/376420a0.

Averof, M., and N.H. Patel. 1997. "Crustacean Appendage Evolution Associated with Changes in Hox Gene Expression." Nature 388 (6643): 682-686. doi:10.1038/41786.

Averof, M., Pavlopoulos, A., and Z. Kontarakis. 2010. "Evolution of New Appendage Types by Gradual Changes in Hox Gene Expression: The Case of Crustacean Maxillipeds." 5.

“BBSRC Business Magazine." 2017. January 1. https://bbsrc.ukri. org/documents/bbsrc-business-winter-2017-pdf/.

Blythe, M.J., Malla, S., Everall, R., Shih, Y.H., Lemay, V., Moreton, J., Wilson, R., and A.A. Aboobaker. 2012. "High ThroughPut Sequencing of the Parhyale hawaiensis MRNAs and microRNAs to Aid Comparative Developmental Studies." PLoS One 7 (3): e33784. doi:10.1371/journal.pone.0033784.

Boxshall, G.A. 2004. "The Evolution of Arthropod Limbs." Biological Reviews of the Cambridge Philosophical Society 79 (2): 253-300. doi:10.1017/s1464793103006274.

Browne, W.E., Price, A.L., Gerberding, M., and N.H. Patel. 2005. "Stages of Embryonic Development in the Amphipod Crustacean, Parhyale hawaiensis." Genesis (New York, N.Y.: 2000) 42 (3): 124-149. doi:10.1002/gene.20145.

Bruce, H.S. 2021. "How to Align Arthropod Leg Segments." BioRxiv, January. Cold Spring Harbor Laboratory, 2021. 01.20.427514. doi:10.1101/2021.01.20.427514.

Bruce, H.S., and N.H. Patel. 2020. "Knockout of Crustacean Leg Patterning Genes Suggests That Insect Wings and Body Walls Evolved from Ancient Leg Segments." Nature Ecology \& Evolution 4 (12): 1703-1712. doi:10.1038/ s41559-020-01349-0.

Chang, W.H., and A.G. Lai. 2018. "Mixed Evolutionary Origins of Endogenous Biomass-Depolymerizing Enzymes in Animals." BMC Genomics 19(1): 483. doi:10.1186/s12864-018-4861-0.

Chaw, R.C., and N.H. Patel. 2012. "Independent Migration of Cell Populations in the Early Gastrulation of the Amphipod Crustacean Parhyale hawaiensis." Developmental Biology 371 (1): 94-109. doi:10.1016/j.ydbio.2012.08.012.
Choi, H.M.T., Schwarzkopf, M., Fornace, M.E., Acharya, A., Artavanis, G., Stegmaier, J., Cunha, A., and N.A. Pierce. 2018. "Third-Generation In Situ Hybridization Chain Reaction: Multiplexed, Quantitative, Sensitive, Versatile, Robust." Development (Cambridge, England) 145 (12). doi:10.1242/ dev.165753.

Clark-Hachtel, C.M., and Y. Tomoyasu. 2016. "Exploring the Origin of Insect Wings from an Evo-Devo Perspective." Current Opinion in Insect Science 13 (February): 77-85. doi:10.1016/j.cois.2015.12.005.

Clark-Hachtel, C.M., and Y. Tomoyasu. 2020. "Two Sets of Candidate Crustacean Wing Homologues and Their Implication for the Origin of Insect Wings." Nature Ecology \& Evolution, August. doi:10.1038/s41559-020-1257-8.

Conlan, K.E. 1991. "Precopulatory Mating Behavior and Sexual Dimorphism in the Amphipod Crustacea." Hydrobiologia 223 (1): 255-282. doi:10.1007/BF00047644.

Copilaş-Ciocianu, D., Borko, Š., and C. Fišer. 2020. "The Late Blooming Amphipods: Global Change Promoted PostJurassic Ecological Radiation Despite Palaeozoic Origin." Molecular Phylogenetics and Evolution 143: 106664. doi:10.1016/j.ympev.2019.106664.

Cormier, A., Chebbi, M.A., Giraud, I., Wattier, R., Teixeira, M., Gilbert, C., Rigaud, T., and R. Cordaux. 2021. "Comparative Genomics of Strictly Vertically Transmitted, Feminizing Microsporidia Endosymbionts of Amphipod Crustaceans." Genome Biology and Evolution 13 (1). doi:10.1093/gbe/evaa245.

Cragg, S.M., Beckham, G.T., Bruce, N.C., Bugg, T.D.H., Distel, D.L., Dupree, P., Green Etxabe, A., Goodell, B.S., Jellison, J., McGeehan, J.E., McQueen-Mason, S.J., Schnorr, K., Walton, P.H., Watts, J.E.M., and M. Zimmer. 2015. "Lignocellulose Degradation Mechanisms across the Tree of Life." Current Opinion in Chemical Biology, Energy • Mechanistic Biology 29 (December): 108-119. doi:10.1016/j.cbpa.2015.10.018.

Dana, J.D. 1853. United States Exploring Expedition: 14: Crustacea. Sherman.

Diehl, O.J., Assano, P.K., da Costa, T.R.G., Oliveira, R., MarquesSouza, H., and G. de Aragão Umbuzeiro. 2021. "Antenna Regeneration as an Ecotoxicological Endpoint in a Marine Amphipod: A Proof of Concept Using Dimethyl Sulfoxide and Diflubenzuron." Ecotoxicology (London, England), March. doi:10.1007/s10646-021-02395-5.

Dohle, W., Gerberding, M., Hejnol, A., and G. Scholtz. 2003. "Cell Lineage, Segment Differentiation, and Gene Expression in Crustaceans." In Evolutionary Developmental Biology of Crustacea. 1st Edition, 95-133. CRC Press. doi:10.13140/ RG.2.1.4984.9841.

Extavour, C.G. 2005. "The Fate of Isolated Blastomeres with Respect to Germ Cell Formation in the Amphipod Crustacean Parhyale hawaiensis." Developmental Biology 277 (2): 387 402. doi:10.1016/j.ydbio.2004.09.030.

Gerberding, M., Browne, W.E., and N.H. Patel. 2002. "Cell Lineage Analysis of the Amphipod Crustacean Parhyale hawaiensis Reveals an Early Restriction of Cell Fates." Development (Cambridge, England) 129 (24): 5789-5801. doi:10.1242/ dev.00155.

Giribet, G., and G.D. Edgecombe. 2019. "The Phylogeny and Evolutionary History of Arthropods." Current Biology: $C B$ 29 (12): R592-602. doi:10.1016/j.cub.2019.04.057.

Grillo, M., Konstantinides, N., and M. Averof. 2016. "Old Questions, New Models: Unraveling Complex Organ Regeneration with New Experimental Approaches." Current Opinion in Genetics \& Development 40 (October): 23-31. doi:10.1016/j. gde.2016.05.006. 
Gupta, T., and C.G. Extavour. 2013. "Identification of a Putative Germ Plasm in the Amphipod Parhyale hawaiensis." EvoDevo 4 (1): 34. doi:10.1186/2041-9139-4-34.

Hannibal, R.L., Price, A.L., and N.H. Patel. 2012. "The Functional Relationship between Ectodermal and Mesodermal Segmentation in the Crustacean, Parhyale hawaiensis." Developmental Biology 361 (2): 427-438. doi:10.1016/j. ydbio.2011.09.033.

Heisenberg, C.P., and Y. Bellaïche. 2013. "Forces in Tissue Morphogenesis and Patterning." Cell 153 (5): 948-962. doi:10.1016/j.cell.2013.05.008.

Holmquist, J.G. 1982. “The Functional Morphology of Gnathopods: Importance in Grooming, and Variation with Regard to Habitat, in Talitroidean Amphipods." Journal of Crustacean Biology 2 (2): 159-179. doi:10.2307/1547997.

Horton, T., Lowry, J., De Broyer, C., Bellan-Santini, D., Coleman, C.O., Corbari, L., Costello, M.J., Daneliya, M., Dauvin, J.C., Fišer, C., Gasca, R., Grabowski, M., Guerra-García, J.M., Hendrycks, E., Hughes, L., Jaume, D., Jazdzewski, K., Kim, Y.H., King, R., Krapp-Schickel, T., LeCroy, S., Lörz, A.N., Mamos, T., Senna, A.R., Serejo, C., Sket, B., Souza-Filho, J.F., Tandberg, A.H., Thomas, J.D., Thurston, M., Vader, W., Väinölä, R., Vonk, R., White, K., and W. Zeidler. 2020. "World Amphipoda Database." www.marinespecies.org/amphipoda/.

Hunnekuhl, V.S., and C. Wolff. 2012. "Reconstruction of Cell Lineage and Spatiotemporal Pattern Formation of the Mesoderm in the Amphipod Crustacean Orchestia cavimana." Developmental Dynamics: An Official Publication of the American Association of Anatomists 241 (4): 697-717. doi:10.1002/dvdy.23758.

Hunt, B.J., Mallon, E.B., and E. Rosato. 2019. "In Silico Identification of a Molecular Circadian System with Novel Features in the Crustacean Model Organism Parhyale hawaiensis." Frontiers in Physiology 10. Frontiers. doi:10. 3389/fphys.2019.01325.

Hyne, R.V. 2011. "Review of the Reproductive Biology of Amphipods and Their Endocrine Regulation: Identification of Mechanistic Pathways for Reproductive Toxicants." Environmental Toxicology and Chemistry 30 (12): 2647 2657. https://doi.org/10.1002/etc.673.

Kaczmarczyk, A.N. 2014. "Germline Maintenance and Regeneration in the Amphipod Crustacean, Parhyale hawaiensis." UC Berkeley. https://escholarship.org/uc/item/5h94b7kg.

Kao, D., Lai, A.G., Stamataki, E., Rosic, S., Konstantinides, N., Jarvis, E., Di Donfrancesco, A., Pouchkina-Stancheva, N., Sémon, M., Grillo, M., Bruce, H., Kumar, S., Siwanowicz, I., Le, A., Lemire, A., Eisen, M.B., Extavour, C., Browne, W.E., Wolff, C., Averof, M., Patel, N.H., Sarkies, P., Pavlopoulos, A., and A. Aboobaker. 2016. "The Genome of the Crustacean Parhyale hawaiensis, a Model for Animal Development, Regeneration, Immunity and Lignocellulose Digestion." ELife 5. doi:10.7554/eLife.20062.

Kern, M., McGeehan, J.E., Streeter, S.D., Martin, R.N.A., Besser, K., Elias, L., Eborall, W., Malyon, G.P., Payne, C.M., Himmel, M.E., Schnorr, K., Beckham, G.T., Cragg, S.M., Bruce, N.C., and S.J. McQueen-Mason. 2013. "Structural Characterization of a Unique Marine Animal Family 7 Cellobiohydrolase Suggests a Mechanism of Cellulase Salt Tolerance." Proceedings of the National Academy of Sciences of the United States of America 110 (25): 10189-10194. doi:10.1073/pnas.1301502110.

King, A.J., Cragg, S.M., Li, Y., Dymond, J., Guille, M.J., Bowles, D.J., Bruce, N.C., Graham, I.A., and S.J. McQueen-Mason. 2010. "Molecular Insight into Lignocellulose Digestion by a Marine Isopod in the Absence of Gut Microbes." Proceedings of the National Academy of Sciences of the
United States of America 107 (12): 5345-5350. doi:10.1073/ pnas.0914228107.

Konstantinides, N., and M. Averof. 2014. "A Common Cellular Basis for Muscle Regeneration in Arthropods and Vertebrates." Science (New York, N.Y.) 343 (6172): 788-791. doi:10.1126/science. 1243529.

Kontarakis, Z., Konstantinides, N., Pavlopoulos, A., and M. Averof. 2011a. "Reconfiguring Gene Traps for New Tasks Using ITRAC." Fly 5 (4): 352-355. doi:10.4161/fly.5.4.18108.

Kontarakis, Z., and A. Pavlopoulos. 2014. "Transgenesis in Non-Model Organisms: The Case of Parhyale." Methods in Molecular Biology (Clifton, N.J.) 1196: 145-181. doi:10.1007/978-1-4939-1242-1_10.

Kontarakis, Z., Pavlopoulos, A., Kiupakis, A., Konstantinides, N., Douris, V., and M. Averof. 2011b. "A Versatile Strategy for Gene Trapping and Trap Conversion in Emerging Model Organisms." Development (Cambridge, England) 138 (12): 2625-2630. doi:10.1242/dev.066324.

Lai, A.G., and A.A. Aboobaker. 2017. "Comparative Genomic Analysis of Innate Immunity Reveals Novel and Conserved Components in Crustacean Food Crop Species." BMC Genomics 18 (1): 389. doi:10.1186/s12864-017-3769-4.

Liubicich, D.M., Serano, J.M., Pavlopoulos, A., Kontarakis, Z., Protas, M.E., Kwan, E., Chatterjee, S., Tran, K.D., Averof, M., and N.H. Patel. 2009. "Knockdown of Parhyale Ultrabithorax Recapitulates Evolutionary Changes in Crustacean Appendage Morphology." Proceedings of the National Academy of Sciences of the United States of America 106 (33): 13892-13896. doi:10.1073/pnas.0903105106.

Lozano-Fernandez, J., Giacomelli, M., Fleming, J.F., Chen, A., Vinther, J., Thomsen, P.F., Glenner, H., Palero, F., Legg, D.A., Iliffe, T.M., Pisani, D., and J. Olesen. 2019. "Pancrustacean Evolution Illuminated by Taxon-Rich Genomic-Scale Data Sets with an Expanded Remipede Sampling." Genome Biology and Evolution 11 (8). Oxford Academic: 2055-70. doi:10.1093/gbe/evz097.

Martin, A., Serano, J.M., Jarvis, E., Bruce, H.S., Wang, J., Ray, S., Barker, C.A., O'Connell, L.C., and N.H. Patel. 2016. "CRISPR/ Cas9 Mutagenesis Reveals Versatile Roles of Hox Genes in Crustacean Limb Specification and Evolution." Current Biology: CB 26 (1): 14-26. doi:10.1016/j.cub.2015.11.021.

McKenna, K.Z., Wagner, G.P., and K.L. Cooper. 2021. "A Developmental Perspective of Homology and Evolutionary Novelty." Current Topics in Developmental Biology 141: 1-38. doi:10.1016/bs.ctdb.2020.12.001.

Modrell, M.S. 2007. "Early Cell Fate Specification in the Amphipod Crustacean, Parhyale hawaiensis." UC Berkeley.

Myers, A.A. 1985. "Shallow-Water, Coral Reef and Mangrove Amphipoda (Gammaridea) of Fiji." Records of the Australian Museum, Supplement 5 (December). The Australian Museum: 1-143. doi:10.3853/j.0812-7387.5.1985.99.

Nast, A.R., and C.G. Extavour. 2014. "Ablation of a Single Cell from Eight-Cell Embryos of the Amphipod Crustacean Parhyale hawaiensis." Journal of Visualized Experiments: JoVE (85) (March). doi:10.3791/51073.

Nestorov, P., Battke, F., Levesque, M.P., and M. Gerberding. 2013. "The Maternal Transcriptome of the Crustacean Parhyale hawaiensis Is Inherited Asymmetrically to Invariant Cell Lineages of the Ectoderm and Mesoderm." PLoS One 8 (2): e56049. doi:10.1371/journal.pone.0056049.

Oakley, T.H., Wolfe, J.M., Lindgren, A.R., and A.K. Zaharoff. 2013. "Phylotranscriptomics to Bring the Understudied into the Fold: Monophyletic Ostracoda, Fossil Placement, and Pancrustacean Phylogeny." Molecular Biology and Evolution 30 (1). Oxford Academic: 215-233. doi:10.1093/molbev/ mss 216 . 
Ozhan-Kizil, G., Havemann, J., and M. Gerberding. 2009. “Germ Cells in the Crustacean Parhyale hawaiensis Depend on Vasa Protein for Their Maintenance but Not for Their Formation." Developmental Biology 327 (1): 230-239. doi:10.1016/j. ydbio.2008.10.028.

Parchem, R.J., Poulin, F., Stuart, A.B., Amemiya, C.T., and N.H. Patel. 2010. "BAC Library for the Amphipod Crustacean, Parhyale hawaiensis." Genomics 95 (5): 261-267. doi:10.1016/j.ygeno.2010.03.005.

Patra, A.K., Chung, O., Yoo, J.Y., Baek, S.H., Jung, T.W., Kim, M.S., Yoon, M.G., Yang, Y., and J.H. Choi. 2020a. "The Draft Genome Sequence of a New Land-Hopper Platorchestia hallaensis." Frontiers in Genetics 11: 621301. doi:10.3389/ fgene.2020.621301.

Patra, A.K., Chung, O., Yoo, J.Y., Kim, M.S., Yoon, M.G., Choi, J.H., and Y. Yang. 2020b. "First Draft Genome for the SandHopper Trinorchestia longiramus." Scientific Data 7 (1): 85. doi:10.1038/s41597-020-0424-8.

Pavlopoulos, A., and M. Averof. 2005. "Establishing Genetic Transformation for Comparative Developmental Studies in the Crustacean Parhyale hawaiensis." Proceedings of the National Academy of Sciences of the United States of America 102 (22): 7888-7893. doi:10.1073/pnas.0501101102.

Pavlopoulos, A., Kontarakis, Z., Liubicich, D.M., Serano, J.M., Akam, M., Patel, N.H., and M. Averof. 2009. "Probing the Evolution of Appendage Specialization by Hox Gene Misexpression in an Emerging Model Crustacean." Proceedings of the National Academy of Sciences of the United States of America 106 (33): 13897-13902. doi:10.1073/pnas.0902804106.

Pavlopoulos, A., Oehler, S., Kapetanaki, M.G., and C. Savakis. 2007. "The DNA Transposon Minos as a Tool for Transgenesis and Functional Genomic Analysis in Vertebrates and Invertebrates." Genome Biology 8 (Suppl 1): S2. doi:10.1186/gb-2007-8-s1-s2.

Pavlopoulos, A., and C. Wolff. 2020. "Crustacean Limb Morphogenesis during Normal Development and Regeneration." In The Natural History of the Crustacea: Developmental Biology and Larval Ecology, edited by Klaus Anger, Steffen Harzsch, and Martin Thiel. Vol. 7. Oxford: Oxford University Press.

Poovachiranon, S., Boto, K., and N. Duke. 1986. "Food Preference Studies and Ingestion Rate Measurements of the Mangrove Amphipod Parhyale hawaiensis (Dana)." Journal of Experimental Marine Biology and Ecology 98 (1): 129-140. doi:10.1016/0022-0981(86)90078-X.

Poynton, H.C., Hasenbein, S., Benoit, J.B., Sepulveda, M.S., Poelchau, M.F., Hughes, D.S.T., Murali, S.C., Chen, S., Glastad, K.M., Goodisman, M.A.D., Werren, J.H., Vineis, J.H., Bowen, J.L., Friedrich, M., Jones, J., Robertson, H.M., Feyereisen, R., Mechler-Hickson, A., Mathers, N., Lee, C.E., Colbourne, J.K., Biales, A., Johnston, J.S., Wellborn, G.A., Rosendale, A.J., Cridge, A.G., Munoz-Torres, M.C., Bain, P.A., Manny, A.R., Major, K.M., Lambert, F.N., Vulpe, C.D., Tuck, P., Blalock, B.J., Lin, Y.Y., Smith, M.E., Ochoa-Acuña, H., Chen, M.J.M., Childers, C.P., Qu, J., Dugan, S., Lee, S.L., Chao, H., Dinh, H., Han, Y., Doddapaneni, H., Worley, K.C., Muzny, D.M., Gibbs, R.A., and S. Richards. 2018. "The Toxicogenome of Hyalella azteca: A Model for Sediment Ecotoxicology and Evolutionary Toxicology." Environmental Science \& Technology 52 (10): 6009-6022. doi:10.1021/acs. est.8b00837.

Price, A.L., Modrell, M.S., Hannibal, R.L., and N.H. Patel. 2010. "Mesoderm and Ectoderm Lineages in the Crustacean Parhyale hawaiensis Display Intra-Germ Layer Compensation.” Developmental Biology 341 (1): 256-266. doi:10.1016/j.ydbio.2009.12.006.
Price, A.L., and N.H. Patel. 2008. "Investigating Divergent Mechanisms of Mesoderm Development in Arthropods: The Expression of Ph-Twist and Ph-Mef2 in Parhyale hawaiensis." Journal of Experimental Zoology: Part B, Molecular and Developmental Evolution 310 (1): 24-40. doi:10.1002/ jez.b.21135.

Putnam, N.H., O'Connell, B.L., Stites, J.C., Rice, B.J., Blanchette, M., Calef, R., Troll, C.J., Fields, A., Hartley, P.D., Sugnet, C.W., Haussler, D., Rokhsar, D.S., and R.E. Green. 2016. "Chromosome-Scale Shotgun Assembly Using an In Vitro Method for Long-Range Linkage." Genome Research 26 (3): 342-350. doi:10.1101/gr.193474.115.

Ramos, A.P., Gustafsson, O., Labert, N., Salecker, I., Nilsson, D.E., and M. Averof. 2019. "Analysis of the Genetically Tractable Crustacean Parhyale hawaiensis Reveals the Organisation of a Sensory System for Low-Resolution Vision." BMC Biology 17 (1): 67. doi:10.1186/s12915-019-0676-y.

Regier, J.C., Shultz, J.W., Zwick, A., Hussey, A., Ball, B., Wetzer, R., Martin, J.W., and C.W. Cunningham. 2010. "Arthropod Relationships Revealed by Phylogenomic Analysis of Nuclear Protein-Coding Sequences." Nature 463 (7284). Nature Publishing Group: 1079-1083. doi:10.1038/nature08742.

Rehm, J.E., Hannibal, R.L., Chaw, C.R., Vargas-Vila, M.A., and N.H. Patel. 2009a. "Antibody Staining of Parhyale hawaiensis Embryos." Cold Spring Harbor Protocols 2009 (1): pdb. prot5129. doi:10.1101/pdb.prot5129.

Rehm, J.E., Hannibal, R.L., Chaw, C.R., Vargas-Vila, M.A., and N.H. Patel. 2009b. "Fixation and Dissection of Parhyale hawaiensis Embryos." Cold Spring Harbor Protocols 2009 (1): pdb.prot5127. doi:10.1101/pdb.prot5127.

Rehm, J.E., Hannibal, R.L., Chaw, C.R., Vargas-Vila, M.A., and N.H. Patel. 2009c. "In Situ Hybridization of Labeled RNA Probes to Fixed Parhyale hawaiensis Embryos." Cold Spring Harbor Protocols 2009 (1): pdb.prot5130. doi:10.1101/pdb. prot5130.

Rehm, J.E., Hannibal, R.L., Chaw, C.R., Vargas-Vila, M.A., and N.H. Patel. 2009d. "Injection of Parhyale hawaiensis Blastomeres with Fluorescently Labeled Tracers." Cold Spring Harbor Protocols 2009 (1): pdb.prot5128. doi:10.1101/pdb.prot5128.

Rehm, J.E., Hannibal, R.L., Chaw, C.R., Vargas-Vila, M.A., and N.H. Patel. 2009e. "The Crustacean Parhyale hawaiensis: A New Model for Arthropod Development." Cold Spring Harbor Protocols 2009 (1): pdb.emo114. doi:10.1101/pdb.emo114.

Robinson, J.T., Thorvaldsdóttir, H., Winckler, W., Guttman, M., Lander, E.S., Getz, G., and J.P. Mesirov. 2011. "Integrative Genomics Viewer." Nature Biotechnology 29 (1): 24-26. doi:10.1038/nbt.1754.

Salvador-Martínez, I., Grillo, M., Averof, M., and M.J. Telford. 2020. "CeLaVi: An Interactive Cell Lineage Visualisation Tool." BioRxiv, December. Cold Spring Harbor Laboratory, 2020.12.14.422765. doi:10.1101/2020.12.14.422765.

Schmitz, E.H., and P.M. Scherrey. 1983. "Digestive Anatomy of Halella azteca (Crustacea, Amphipoda)." Journal of Morphology 175 (1): 91-100. doi:10.1002/jmor.1051750109.

Schwentner, M., Combosch, D.J., Pakes Nelson, J., and G. Giribet. 2017. "A Phylogenomic Solution to the Origin of Insects by Resolving Crustacean-Hexapod Relationships." Current Biology: CB 27 (12): 1818-1824.e5. doi:10.1016/j.cub.2017.05.040.

Schwentner, M., Richter, S., Rogers, C.D., and G. Giribet. 2018. "Tetraconatan Phylogeny with Special Focus on Malacostraca and Branchiopoda: Highlighting the Strength of Taxon-Specific Matrices in Phylogenomics." Proceedings: Biological Sciences 285 (1885). doi:10.1098/rspb.2018.1524.

Serano, J.M., Martin, A., Liubicich, D.M., Jarvis, E., Bruce, H.S., La, K., Browne, W.E., Grimwood, J., and N.H. Patel. 2016. 
"Comprehensive Analysis of Hox Gene Expression in the Amphipod Crustacean Parhyale hawaiensis." Developmental Biology 409 (1): 297-309. doi:10.1016/j.ydbio.2015.10.029. Shoemaker, C.R. 1956. "Observations on the Amphipod Genus Parhyale." http://repository.si.edu/xmlui/handle/10088/16629.

Stamataki, E., and A. Pavlopoulos. 2016. "Non-Insect Crustacean Models in Developmental Genetics Including an Encomium to Parhyale hawaiensis." Current Opinion in Genetics \& Development 39: 149-156. doi:10.1016/j.gde.2016.07.004.

Sugawara, K., Cevrim, C., and M. Averof. 2021. "Tracking Cell Lineages in 3D by Incremental Deep Learning." BioRxiv, February. Cold Spring Harbor Laboratory, 2021. 02.26.432552. doi:10.1101/2021.02.26.432552.

Tanaka, E. M., and P. W. Reddien. 2011. "The Cellular Basis for Animal Regeneration.” Developmental Cell 21 (1): 172-185. doi:10.1016/j.devcel.2011.06.016.

Tararam, A.S., Wakabara, Y., and F.P.P. Leite. 1978. "Notes on Parhyale hawaiensis (Dana), Crustacea-Amphipoda." Bulletin of Marine Science 28 (4): 782-786.

Trapp, J., Almunia, C., Gaillard, J.C., Pible, O., Chaumot, A., Geffard, O., and J. Armengaud. 2016. "Proteogenomic Insights into the Core-Proteome of Female Reproductive Tissues from Crustacean Amphipods." Journal of Proteomics, Proteomics in Evolutionary Ecology, 135 (March): 51-61. doi:10.1016/j.jprot.2015.06.017.

Vargas-Vila, M.A., Hannibal, R.L., Parchem, R.J., Liu, P.Z., and N.H. Patel. 2010. "A Prominent Requirement for Single-Minded and the Ventral Midline in Patterning the Dorsoventral Axis of the Crustacean Parhyale hawaiensis." Development (Cambridge, England) 137 (20): 3469-3476. doi:10.1242/dev.055160.

von Reumont, B.M., Jenner, R.A., Wills, M.A., Dell'Ampio, E., Pass, G., Ebersberger, I., Meyer, B., Koenemann, S., Iliffe,
T.M., Stamatakis, A., Niehuis, O., Meusemann, K., and B. Misof. 2012. "Pancrustacean Phylogeny in the Light of New Phylogenomic Data: Support for Remipedia as the Possible Sister Group of Hexapoda." Molecular Biology and Evolution 29 (3). Oxford Academic: 1031-1045. doi:10.1093/molbev/ msr270.

Wan, Y., McDole, K., and P.J. Keller. 2019. "Light-Sheet Microscopy and Its Potential for Understanding Developmental Processes." Annual Review of Cell and Developmental Biology 35: 655681. doi:10.1146/annurev-cellbio-100818-125311.

Wiese, K. 2002. The Crustacean Nervous System. Berlin, Heidelberg: Springer-Verlag. www.springer.com/gp/book/9783540669005.

Wittfoth, C., Harzsch, S., Wolff, C., and A. Sombke. 2019. "The 'Amphi'-Brains of Amphipods: New Insights from the Neuroanatomy of Parhyale hawaiensis (Dana, 1853)." Frontiers in Zoology 16: 30. doi:10.1186/s12983-019-0330-0.

Wolff, C., Tinevez, J.Y., Pietzsch, T., Stamataki, E., Harich, B., Guignard, L., Preibisch, S., Shorte, S., Keller, P.J., Tomancak, P., and A. Pavlopoulos. 2018. "Multi-View Light-Sheet Imaging and Tracking with the MaMuT Software Reveals the Cell Lineage of a Direct Developing Arthropod Limb." ELife 7. doi:10.7554/eLife.34410.

Zeng, V., and C.G. Extavour. 2012. "ASGARD: An Open-Access Database of Annotated Transcriptomes for Emerging Model Arthropod Species." Database: The Journal of Biological Databases and Curation 2012: bas048. doi:10.1093/ database/bas048.

Zeng, V., Villanueva, K.E., Ewen-Campen, B.S., Alwes, F., Browne, W.E., and C.G. Extavour. 2011. "De Novo Assembly and Characterization of a Maternal and Developmental Transcriptome for the Emerging Model Crustacean Parhyale hawaiensis." BMC Genomics 12 (November): 581. doi:10.1186/1471-2164-12-581. 